\title{
Crack Initiation Criteria in EBC under Thermal Stress
}

\author{
Emi Kawai ${ }^{1}$, Hideki Kakisawa ${ }^{2}$, Atsushi Kubo ${ }^{3}$, Norio Yamaguchi ${ }^{1}$, Taishi Yokoi ${ }^{4}$, \\ Takashi Akatsu ${ }^{5}$ (D), Satoshi Kitaoka ${ }^{1}$ and Yoshitaka Umeno ${ }^{3, *}$ \\ 1 Japan Fine Ceramics Center, Nagoya 456-8587, Japan; emi_kawai@jfcc.or.jp (E.K.); \\ yamaguchi@jfcc.or.jp (N.Y.); kitaoka@jfcc.or.jp (S.K.) \\ 2 National Institute for Materials Science, Ibaraki 305-0047, Japan; KAKISAWA.Hideki@nims.go.jp \\ 3 Institute of Industrial Science, The University of Tokyo, Tokyo 153-8505, Japan; kubo@ulab.iis.u-tokyo.ac.jp \\ 4 Institute of Biomaterials and Bioengineering, Tokyo Medical and Dental University, Tokyo 101-0062, Japan; \\ yokoi.taishi.bcr@tmd.ac.jp \\ 5 Faculty of Art and Regional Design, Saga University, Saga 840-8502, Japan; akatsu@cc.saga-u.ac.jp \\ * Correspondence: umeno@iis.u-tokyo.ac.jp; Tel.: +81-3-5452-6902
}

Received: 12 September 2019; Accepted: 21 October 2019; Published: 24 October 2019

\begin{abstract}
For design of multi-layered environmental barrier coatings (EBCs), it is essential to assure mechanical reliability against interface crack initiation and propagation induced by thermal stress owing to a misfit of the coefficients of thermal expansion between the coating layers and $\mathrm{SiC} / \mathrm{SiC}$ substrate. We conducted finite element method (FEM) analyses to evaluate energy release rate (ERR) for interface cracks and performed experiment to obtain interface fracture toughness to assess mechanical reliability of an EBC with a function of thermal barrier (T/EBC; SiC/SiAlON/mullite/Yb-silicate gradient composition layer $/ \mathrm{Yb}_{2} \mathrm{SiO}_{5}$ with porous segment structure) on an $\mathrm{SiC} / \mathrm{SiC}$ substrate under thermal stress due to cooling in fabrication process. Our FEM analysis revealed that a thinner SiAlON layer and a thicker mullite layer are most suitable to reduce ERRs for crack initiation at the $\mathrm{SiC} / \mathrm{SiAlON}, \mathrm{SiAlON} / \mathrm{mullite}$ and mullite $/ \mathrm{Yb}_{2} \mathrm{Si}_{2} \mathrm{O}_{7}$ interfaces. Interface fracture tests of the $\mathrm{T} / \mathrm{EBC}$ with layer thicknesses within the proposed range exhibited fracture at the SiC/SiAlON and $\mathrm{SiAlON} /$ mullite interfaces. We also estimated the approximate fracture toughness for the SiC/SiAlON and $\mathrm{SiAlON} / \mathrm{mullite}$ interfaces and lower limit of fracture toughness for the mullite/ $\mathrm{Yb}_{2} \mathrm{Si}_{2} \mathrm{O}_{7}$ interface. Comparison between ERR and fracture toughness indicates that the fabricated T/EBC possesses sufficient mechanical reliability against interface crack initiation and propagation.
\end{abstract}

Keywords: fabrication process; layer thickness design; interface crack initiation/propagation; fracture toughness; energy release rate; finite element method analysis

\section{Introduction}

Silicon carbide $(\mathrm{SiC})$ fiber reinforced $\mathrm{SiC}$ matrix $(\mathrm{SiC} / \mathrm{SiC})$ composites are one-third lighter and have approximate 100-200 K higher heat resistance than current heat-resistant super alloys (Nickel-based super alloys) [1-3]. Application of $\mathrm{SiC} / \mathrm{SiC}$ to advanced hot-section components in airplane engines is expected for improving fuel consumption and curbing emission of carbon dioxide [2,3]. SiC/SiC composites react with oxygen to form silica, which hinders degradation of the composites at high temperature over 1373-1473 K [4,5]. In the condition of high temperature and humidity (i.e., combustion gas environment), however, the silica reacts with water vapor to form silicic acid $\left(\mathrm{Si}\left(\mathrm{OH}_{4}\right)\right)$ gas $[4,5]$, leading to wall thinning of the composites. Thus, application of the $\mathrm{SiC} / \mathrm{SiC}$ composites to the hot-section components inevitably requires environmental barrier coatings (EBCs).

To achieve superior environmental shielding performance and thermomechanical durability, EBCs consist of several layers with different shielding functions [6,7]. For using EBCs at about $1673 \mathrm{~K}$, which is the durable temperature of the heat-resistant $\mathrm{SiC}$ fiber, it is of immense importance to select a material 
with the following properties as the water vapor shielding layer; significant wall-thinning resistance in the combustion gas environment, and coefficients of thermal expansion (CTEs) being close to that of the $\mathrm{SiC} / \mathrm{SiC}$. Klemm conducted burner-rig tests for various heat-resistant materials under the condition simulating the actual combustion gas environment to quantitatively evaluate relationship between CTEs and wall-thinning rate [8]. The result indicated that ytterbium silicate $\left(\mathrm{Yb}_{2} \mathrm{SiO}_{5} ; \mathrm{YbMS}\right.$ and $\mathrm{Yb}_{2} \mathrm{Si}_{2} \mathrm{O}_{7} ; \mathrm{YbDS}$ ) has prominent wall-thinning resistance. He reported that the resistance of $\mathrm{YbMS}$ is particularly outstanding and that the CTE of YbMS is slightly larger than that of the $\mathrm{SiC} / \mathrm{SiC}$ substrate, which is almost equal to that of YbDS. Yb-silicate is unlikely to fracture by phase transition during thermal cycle because phase transition causing the large volume change does not appear in the material throughout a wide temperature range from room temperature to high temperature. On the basis of these features, $\mathrm{Yb}$-silicate is considered to be an attractive material as the water vapor shielding layer. By the way, $\mathrm{YbMS}$ is expected to be applied as the thermal barrier coating (TBC) for $\mathrm{SiC} / \mathrm{SiC}$ substrate because the thermal conductivity of YbMS [9] is smaller than that of $\mathrm{Y}_{2} \mathrm{O}_{3}-\mathrm{ZrO}_{2}$ (YSZ), which is used as TBC for Nickel-based super alloys.

Under the combustion gas environment, EBCs are exposed to a steep gradient of oxygen chemical potential $\left(d \mu_{\mathrm{O}}\right)$. It is known that, in an oxide layer under the environment of high temperature and $d \mu_{\mathrm{O}}$, the oxide ion migrates from high oxygen partial pressure $\left(P_{\mathrm{O}_{2}}\right)$ to low $P_{\mathrm{O}_{2}}$ while the cation migrates in the opposite direction following the Gibbs-Duhem equation. This suggests that oxygen permeation occurs because of migration of cations as well as oxide ions. In addition, the cation migration may promote phase decomposition and fracture of the multi-layer component. For improving the phase stability of EBCs, therefore, it is of primary importance to prevent the migration of cations. Kitaoka et al. conducted oxygen permeability tests for representative heat-resistant oxides ( $\mathrm{Al}_{6} \mathrm{Si}_{2} \mathrm{O}_{13}$ (mullite) and $\mathrm{Yb}$-silicate) under high temperature [10-12]. They clarified that the oxygen shielding of mullite was superior to that of $\mathrm{Yb}$-silicate and that the mullite was decomposed due to the motion of $\mathrm{Al}$ ions from the low- $P_{\mathrm{O}_{2}}$ to high- $P_{\mathrm{O}_{2}}$ side producing deficiency of $\mathrm{Al}$ ions in the layer on the low- $P_{\mathrm{O}_{2}}$ side. Kitaoka et al. demonstrated that the phase of mullite is stabilized by depositing a SiAlON layer on the low- $P_{\mathrm{O}_{2}}$ side of the mullite layer because it feeds $\mathrm{Al}$ ions [13].

On the basis of the abovementioned studies, we propose an EBC with a function of thermal barrier as shown in Figure 1, which we call T/EBC hereafter. The structure consists of layers as follows (in order from the side of $\mathrm{SiC} / \mathrm{SiC}$ substrate); the $\mathrm{SiC}$ layer for smoothing the surface of the substrate, the SiAlON layer for bonding with the substrate and ensuring structural stability of the mullite, the mullite dense layer for oxygen shielding, the $\mathrm{Yb}$-silicate dense layer for water vapor shielding, and the layer of YbMS with porous segment structure for thermal shock resistance. Here, for decreasing thermal stress that occurs by the difference in CTEs of the coating layers and the substrate, the Yb-silicate dense layer is formed with gradient composition to have YbDS and YbMS on the substrate and top sides, respectively. Hereafter it is referred to as the $\mathrm{Yb}$-silicate gradient composition layer. The topmost YbMS layer with a porous segment structure (topcoat) is employed for thermal shock resistance so as to relax strain due to rapid temperature change in the thickness direction associated with start and stop of the engine.

$\mathrm{T} / \mathrm{EBC}$ is fabricated by depositing these layers on a $\mathrm{SiC} / \mathrm{SiC}$ substrate at high temperature and cooling it to room temperature. During the cooling process, the thermal stress may cause interface crack initiation/propagation and delamination along interfaces between the layers with the function of environmental barrier. This leads to deterioration of the mechanical reliability of T/EBC. Thus, it is essential to design $\mathrm{T} / \mathrm{EBC}$ in such a way that crack initiation and propagation are prevented during the cooling process. 


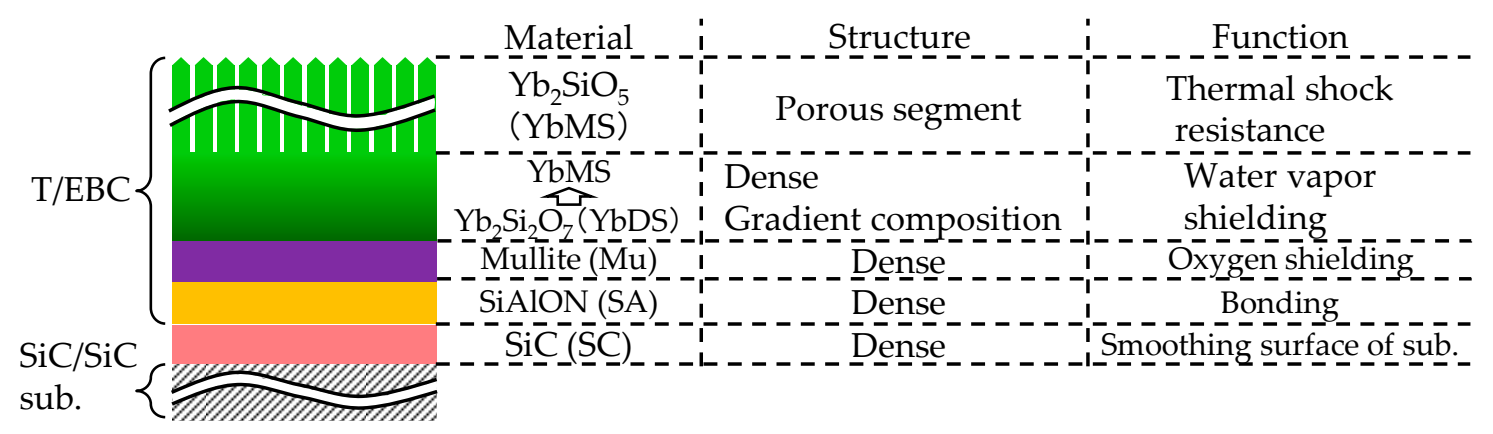

Figure 1. Schematic of thermal/environmental barrier coating (T/EBC) consisting of SiAlON (SA; bonding layer), mullite (Mu; oxygen shielding), layer of gradient composition of $\mathrm{Yb}_{2} \mathrm{SiO}_{5}(\mathrm{YbMS})$ and $\mathrm{Yb}_{2} \mathrm{Si}_{2} \mathrm{O}_{7}$ (YbDS) (Yb-silicate gradient composition layer; water vapor shielding) and top $\mathrm{YbMS}$ with porous segment structure (thermal shock resistance).

In general, fracture of brittle materials follows the Griffith theory; i.e., a crack initiates or propagates when the energy release rate (ERR) exceeds fracture toughness for the corresponding fracture mode. While fracture toughness is a material property that should be evaluated in experiments, ERR can be calculated by numerical simulations through, for example, finite element method (FEM) calculations. Unlike conventional TBCs having simple structures, the mechanical behavior of T/EBC is expected to be complicated due to its complex structure consisting of multiple layers on a substrate. Numerical simulation can be an efficient tool to evaluate ERR even in such a complex structure.

In designing T/EBC structure with sufficient mechanical reliability, we must optimize a wide range of parameters, including conditions of multi-layer deposition processes and structural dimensions such as layer thicknesses. Layer thicknesses should affect much the mechanical state and play a crucial role in the mechanical stability of T/EBC under thermomechanical loading, which the component should undergo in operation. It is of importance to understand how such structural parameters influence the mechanical reliability. The aim of this study is to propose the condition of layer thicknesses for preventing interface crack initiation and propagation during the cooling process in the fabrication of the T/EBC. We perform FEM analysis for a T/EBC model with varying thicknesses of the coating layers to investigate the dependence of the layer thicknesses on ERR of crack initiation at interfaces, where thermal stress concentrates significantly. The analysis result facilitates the determination of layer thicknesses to prevent interface crack initiation. Then, the T/EBC is fabricated within the proposed thicknesses of the coating layers. We calculate ERR for interface crack initiation and propagation by conducting FEM analysis to a model of the fabricated T/EBC. Comparing the ERRs and fracture toughness obtained by interface fracture tests, we assess the validity of the proposed layer thicknesses.

\section{Experiment and Simulation Procedures}

\subsection{Fabrication Procedure of $T / E B C$}

In this study, the substrate was $\mathrm{SiC} / \mathrm{SiC}$ ( $50 \mathrm{~mm}$ square and $3 \mathrm{~mm}$ in thickness) whose matrix was formed by chemical vapor infiltration and subsequent melt infiltration. Before T/EBC deposition, a SiC layer with an adequate thickness was deposited by chemical vapor deposition in order to smoothen the surface to be coated.

Each constituent layer of T/EBC shown in Figure 1 is a complex oxide or an oxynitride containing multiple cations. When these compounds are heated to a high temperature, the composition of vapor containing cation differs substantially from that of compounds in solid phase (incongruent vaporization). Thus, deposition methods accompanying the melting process of raw materials, such as plasma spraying, bring about the incongruent vaporization of the materials during deposition, resulting in significantly deviated compositions of coating layers. 
In this study, therefore, dual electron beam-physical vapor deposition (EB-PVD) was employed to prepare layers of compounds which were evaporated incongruently. Two target raw materials located in the deposition chamber were evaporated using two electron guns regulated individually, which enabled independent control of vapor pressures of gases generated from the targets. Compound layers with arbitrary compositions were deposited on a substrate placed at a proper distance from the targets. During deposition, small amount of source gas was introduced in the coating chamber, and the coated surface was heated up to about $1473 \mathrm{~K}$ by irradiation of a direct diode laser (wavelength of $915 \mathrm{~nm}$ ) to promote full crystallization and densification of each layer. After the deposition finished, the specimen was cooled from the deposition temperature to room temperature at the average cooling rate of $20 \mathrm{~K} / \mathrm{min}$.

Table 1 lists the target materials (Ingots A and B) and source gases used in the deposition of the layers. During deposition of the $\mathrm{Yb}$-silicate gradient composition layer, the ratio of two electron beam powers irradiated to two targets was gradually changed with coating time to control the composition toward the thickness direction. The YbMS topcoat was deposited on a rotating sample for out-of-surface to form the porous segmented structure owing to the shadowing effect.

Table 1. Raw material targets and source gases for preparation of T/EBC.

\begin{tabular}{cccc}
\hline \multirow{2}{*}{ Coating Layer } & \multicolumn{2}{c}{ Raw Material Targets } & \multirow{2}{*}{ Source Gas } \\
\cline { 2 - 3 } & Ingot $\mathbf{A}$ & Ingot $\mathbf{B}$ & \\
\hline $\mathrm{SA}$ & $\mathrm{Al}_{2} \mathrm{O}_{3}$ & $\mathrm{Si}$ & $\mathrm{NH}_{3}$ \\
$\mathrm{Mu}$ & $\mathrm{Al}_{2} \mathrm{O}_{3}$ & $\mathrm{SiO}_{2}$ & $\mathrm{O}_{2}$ \\
Yb-silicate gradient composition & $\mathrm{Yb}_{2} \mathrm{O}_{3}$ & $\mathrm{SiO}_{2}$ & $\mathrm{O}_{2}$ \\
YbMS with porous segment structure & $\mathrm{Yb}_{2} \mathrm{O}_{3}$ & $\mathrm{SiO}_{2}$ & $\mathrm{O}_{2}$ \\
\hline
\end{tabular}

The cross-sectional microstructure of T/EBCs was observed using a scanning electron microscope (SEM; SU8000 SEM, HITACHI, Tokyo, Japan) with energy dispersive spectroscopy (EDS).

\subsection{ERR Calculation by FEM Analysis}

For ensuring the mechanical reliability of T/EBC in the fabrication procedure, we need to determine its layer thicknesses with which ERR for interface crack initiation due to the thermal stress, $\mathcal{G}_{\text {init' }}^{\text {th }}$ can be reduced so that interface crack is not likely to initiate. In general, it is difficult to fabricate T/EBC without any initial interface crack such as microcrack. Thus, under the proposed layer thicknesses for preventing interface crack initiation, evaluating the behavior of interface crack propagation is also required. This means that we need to calculate ERR for interface crack propagation due to the thermal stress, $\mathcal{G}_{\text {prop }}^{\text {th }}$, and compare with it and interface fracture toughness.

In this study, in order to investigate the effect of layer thicknesses on $\mathcal{G}_{\text {init }^{\text {th }}}$, we conducted two-step FEM analyses using a T/EBC model with varying layer thickness; (1) Thermal stress analysis: FEM analysis for evaluating the thermal stress state after the cooling process and (2) Interface crack introduction analysis: FEM analysis for calculating ERR by introducing interface crack in the thermal stress state that was obtained in Step (1). Then, for obtaining $\mathcal{G}_{\text {prop }}^{\text {th }}$, we conducted the two-step FEM analyses to the T/EBC model with the optimized layer thickness to prevent interface crack initiation. ABAQUS (ver.6.14.6, Dassault Systemes, Vélizy-Villacoublay, France) was used in the calculations.

\subsubsection{FEM Model of T/EBC}

The state of thermal stress in T/EBC is affected by the thicknesses of the coating layers. In particular, the difference in CTEs of the SiAlON and mullite layers is large compared to those at other interfaces (CTEs are explained in Section 2.2.2), and thus the thicknesses of the SiAlON and mullite layers are expected to significantly affect the state of thermal stress after cooling. We examined the simulation models mimicking T/EBC with various thicknesses of the SiAlON and mullite layers as shown in 
Figure 2. Note that the FEM model used in this analysis is a model of the vicinity of interface edge of T/EBC deposited sample, which is indicated by a blue rectangle in Figure 2.

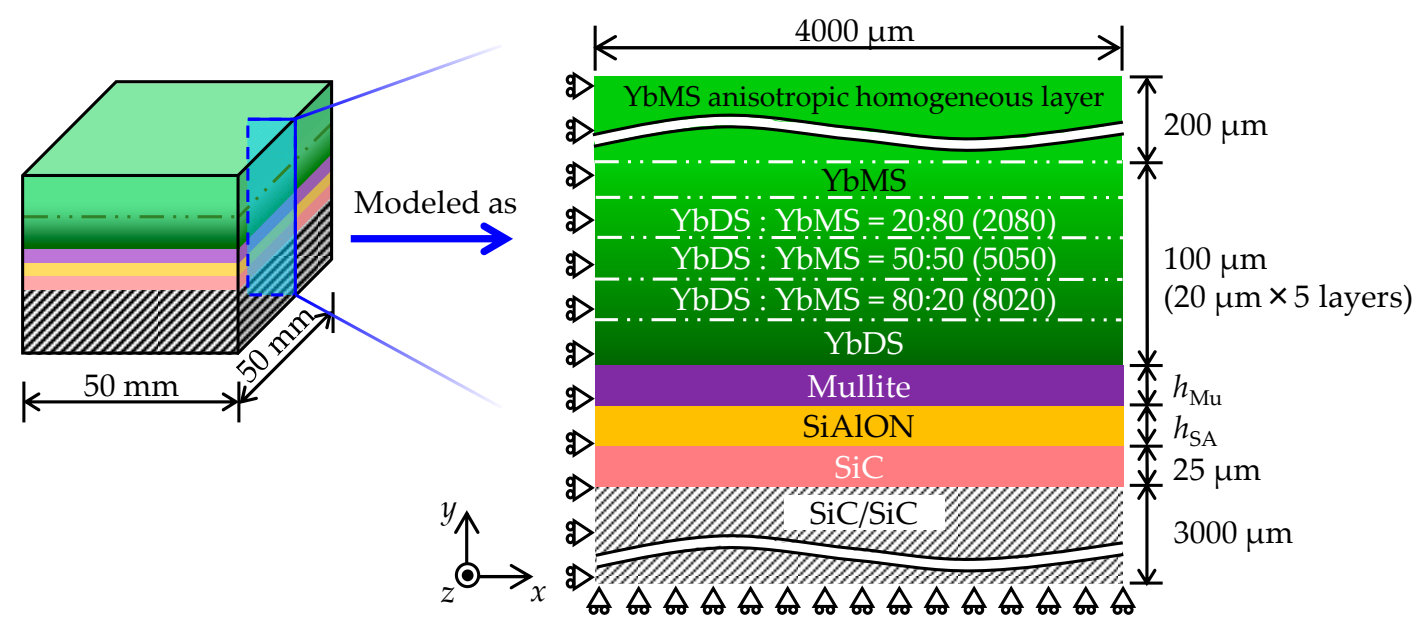

Figure 2. Schematic illustration of finite element method (FEM) analyses model and boundary condition.

In this study, the $\mathrm{Yb}$-silicate gradient composition layer was modeled with five layers with different ratios of the YbDS and YbMS as follows; YbDS:YbMS = 100:0, 80:20, 50:50, 20:80, and 0:100. For computational efficiency and simplicity, the segmented YbMS layer was regarded as a homogenized material with an anisotropic (in-plane isotropic) mechanical property equivalent to the segmented layer [14]; hereafter it is referred to as the YbMS anisotropic homogeneous layer (Figure 2). The $\mathrm{SiC} / \mathrm{SiC}$ substrate was treated as an in-plane isotropic material owing to the orientation of SiC fibers. T/EBC structure was represented by a 2-D simulation model, where displacements of the left and bottom edges of the model along the $x$ and $y$ directions, respectively, (shown in Figure 2) were constrained. A plane strain state was assumed to the $z$ direction. In this analysis, the thicknesses of the SiAlON and mullite layers were changed $(5,15$ and $25 \mu \mathrm{m})$, while the thicknesses of other layers were fixed as below; the SiC, Yb-silicate gradient composition and topcoat YbMS layers were 25, 100 (20 $\mu \mathrm{m}$ times five layers) and $200 \mu \mathrm{m}$, respectively. The thickness and width of the $\mathrm{SiC} / \mathrm{SiC}$ substrate were 3000 and $4000 \mu \mathrm{m}$, respectively. The regions near all interfaces, where strong stress concentration is expected, were divided into a finer mesh $(0.5 \mu \mathrm{m} \times 0.5 \mu \mathrm{m})$.

\subsubsection{Thermal Stress Analysis}

Since the experimental temperature is decreased gradually during the cooling process in fabrication of the T/EBC as explained in Section 2.1, the temperature dependence of the elastic properties (Young' modulus and Poisson's ratio) and the thermal property (CTE) must be taken into account for the thermal stress analysis. In addition, it is necessary to take account of the effect of creep on the mechanical state for the conditions of the experimental temperature and the cooling rate in the present deposition process. Thus, in this study, a series of the thermal stress analyses was carried out to evaluate the thermal stress distribution in $\mathrm{T} / \mathrm{EBC}$, where the creep effect was considered. Thermal stress is accumulated in T/EBC throughout the cooling process; i.e., stress is assumed to be null at the high temperature in the deposition process, and we evaluate the thermal stress state in T/EBC after cooling to room temperature from the high temperature. The thermal stress is dominated by stress in the $x$-axis direction in Figure 2 mainly, and thus the loading parallel to the interface, in other words, mode II-rich thermal loading is applied to T/EBC. 
The temperature condition for this analysis was determined from the experimental condition of the cooling process after deposition of T/EBC (cooling from a high temperature in the deposition process to room temperature at cooling rate of $20 \mathrm{~K} / \mathrm{min}$ ). A uniform temperature distribution in T/EBC was assumed during the cooling process. Although the surface temperature of the coated layers is up to $1473 \mathrm{~K}$ in the deposition process as described in Section 2.1, in this analysis we set the deposition temperature (the initial temperature) to be $1673 \mathrm{~K}$, which is an assumed operation temperature of $\mathrm{T} / \mathrm{EBC}$ and provides an estimation on the safer side. In addition, the cooling rate of $20 \mathrm{~K} / \mathrm{min}$ can cause a considerable effect of creep during the cooling process. In general, it is known that creep emerges significantly at temperatures higher than half the melting point [15]. Thus, in this analysis, the stress was set to be null at the initial state of $1673 \mathrm{~K}$, and the development of stress distribution was calculated at a cooling rate of $20 \mathrm{~K} / \mathrm{min}$ while creep was considered within the temperature range of 1673-1173 K. Creep was assumed to be negligible for $\mathrm{SiC}$ and $\mathrm{SiC} / \mathrm{SiC}$ substrate. Since creep was not taken into account for all materials (i.e., the analysis is independent of time) below $1173 \mathrm{~K}$, the system was cooled immediately from 1173 to $303 \mathrm{~K}$.

As we consider a wide temperature range, we adopted temperature-dependent material properties; Young's modulus, E, Poisson's ratio, $v$, CTE (reference temperature: $1673 \mathrm{~K}$ ), $\alpha^{\prime}$, and creep properties (creep coefficient, $C$, and creep index, $n$ ) listed in Tables $2-8$, respectively. The elastic properties (i.e., $E$ and $v$ ) of the $\mathrm{YbMS}$ anisotropic homogeneous layer and the $\mathrm{SiC} / \mathrm{SiC}$ substrate were regarded as anisotropic from the microstructure and the fiber orientation, respectively. Also, $E$ and $v$ of the mullite layer were regarded as anisotropic on the basis of the experimental result of the in-plane and out-of-plane loading tests on the deposited mullite layer (along the $x$ and $y$ axes in Figure 2, respectively). The other layers were dealt with as isotropic materials. CTE and the creep properties of each layer and substrate were assumed to be isotropic. The temperature-dependent material properties were calculated from experimental measurements and literature (see Appendix A).

Table 2. Young's moduli $(E)$ of isotropic elastic layers.

\begin{tabular}{cccccccc}
\hline & & \multicolumn{5}{c}{ E [GPa] } \\
\cline { 3 - 7 } Temp. & & \multicolumn{5}{c}{ YbDS:YbMS } \\
\cline { 3 - 7 } & SC & SA & $\mathbf{1 0 0 : 0}$ & $\mathbf{8 0 : 2 0}$ & $\mathbf{5 0 : 5 0}$ & $\mathbf{2 0 : 8 0}$ & $\mathbf{0 : 1 0 0}$ \\
\cline { 3 - 8 } & & & 128 & 121 & 111 & 102 & 96.0 \\
303 & 476 & 232 & 128 & 121 & 111 & 102 & 95.9 \\
473 & 474 & 231 & 127 & 120 & 110 & 101 & 95.8 \\
573 & 472 & 229 & 126 & 119 & 110 & 101 & 95.5 \\
673 & 469 & 227 & 125 & 118 & 109 & 100 & 95.0 \\
773 & 467 & 226 & 124 & 117 & 108 & 100 & 94.5 \\
873 & 464 & 224 & 116 & 107 & 99.0 & 93.8 \\
973 & 459 & 223 & 122 & 115 & 106 & 98.1 & 93.0 \\
1073 & 457 & 220 & 120 & 114 & 105 & 97.2 & 92.1 \\
1173 & 454 & 218 & 119 & 113 & 104 & 96.2 & 91.2 \\
1273 & 451 & 217 & 118 & 112 & 103 & 95.1 & 90.2 \\
1373 & 449 & 215 & 116 & 110 & 102 & 94.0 & 89.2 \\
1473 & 446 & 213 & 115 & 109 & 101 & 92.9 & 88.1 \\
1573 & 444 & 212 & 113 & 108 & 99.3 & 91.7 & 86.9 \\
1673 & 441 & 210 & 112 & 106 & 98.0 & 90.4 & 85.7 \\
\hline
\end{tabular}


Table 3. Poisson's ratios (v) of isotropic elastic layers.

\begin{tabular}{cccccccc}
\hline & & \multicolumn{5}{c}{$\boldsymbol{v}$} \\
Temp. & & & \multicolumn{5}{c}{ YbDS:YbMS } \\
\cline { 2 - 7 } $\boldsymbol{T}[\mathbf{K}]$ & SC & SA & $\mathbf{1 0 0 : 0}$ & $\mathbf{8 0 : 2 0}$ & $\mathbf{5 0 : 5 0}$ & $\mathbf{2 0 : 8 0}$ & $\mathbf{0 : 1 0 0}$ \\
\cline { 4 - 8 } & & & 0.26 & 0.25 & 0.25 & 0.24 & $0.23^{1}$ \\
303 & 0.21 & 0.34 & 0.25 & 0.25 & 0.24 & 0.23 & - \\
373 & 0.21 & 0.35 & 0.25 & 0.25 & 0.24 & 0.23 & - \\
473 & 0.21 & 0.35 & 0.25 & 0.23 & - \\
573 & 0.21 & 0.35 & 0.25 & 0.25 & 0.24 & 0.23 & - \\
673 & 0.21 & 0.35 & 0.25 & 0.25 & 0.24 & - \\
773 & 0.21 & 0.35 & 0.25 & 0.25 & 0.24 & 0.23 & - \\
873 & 0.21 & 0.36 & 0.25 & 0.25 & 0.24 & 0.23 & - \\
973 & 0.21 & 0.39 & 0.25 & 0.25 & 0.24 & 0.23 & - \\
1073 & 0.21 & 0.39 & 0.24 & 0.24 & 0.24 & 0.23 & - \\
1173 & 0.21 & 0.39 & 0.24 & 0.24 & 0.24 & 0.23 & - \\
1273 & 0.21 & 0.39 & 0.23 & 0.23 & 0.23 & 0.23 & - \\
1373 & 0.21 & 0.39 & 0.23 & 0.23 & 0.23 & 0.23 & - \\
1473 & 0.20 & 0.39 & 0.23 & 0.23 & 0.23 & 0.23 & - \\
1573 & 0.19 & 0.39 & 0.23 & 0.23 & 0.23 & 0.23 & - \\
1673 & 0.19 & 0.39 & 0.23 & 0.23 & 0.23 & 0.23 & - \\
\hline
\end{tabular}

${ }^{1}$ No temperature dependence is assumed.

Table 4. Elastic properties $(E, v$, and $G)$ of $\mathrm{SiC} / \mathrm{SiC}$ substrate.

\begin{tabular}{cccccccc}
\hline \multirow{2}{*}{ Temp. } & \multicolumn{2}{c}{$E[\mathrm{GPa}]$} & \multicolumn{2}{c}{$\boldsymbol{v}$} & \multicolumn{2}{c}{$\boldsymbol{G}[\mathrm{GPa}]$} \\
\cline { 2 - 8 } $\boldsymbol{T}[\mathbf{K}]$ & $\boldsymbol{E}_{\boldsymbol{x}}$ & $\boldsymbol{E}_{\boldsymbol{y}}$ & $\boldsymbol{v}_{\boldsymbol{x} y}$ & $\boldsymbol{v}_{\boldsymbol{x} z}$ & $\boldsymbol{v}_{\boldsymbol{y} z}$ & $\boldsymbol{G}_{\boldsymbol{x} y}$ & $\boldsymbol{G}_{\boldsymbol{x} z}$ \\
\hline 303 & 150 & 59.9 & $0.25^{1}$ & $0.1^{1}$ & $0.08^{1}$ & 37.5 & 68.1 \\
373 & 147 & 58.9 & - & - & - & 36.8 & 67.0 \\
473 & 144 & 57.5 & - & - & - & 36.0 & 65.4 \\
573 & 140 & 56.1 & - & - & - & 35.1 & 63.8 \\
673 & 137 & 54.7 & - & - & - & 34.2 & 62.2 \\
773 & 133 & 53.3 & - & - & - & 33.3 & 60.6 \\
873 & 130 & 51.9 & - & - & - & 32.4 & 59.0 \\
973 & 126 & 50.5 & - & - & - & 31.5 & 57.4 \\
1073 & 123 & 49.1 & - & - & - & 30.7 & 55.7 \\
1173 & 119 & 47.7 & - & - & - & 29.8 & 54.1 \\
1273 & 116 & 46.3 & - & - & - & 28.9 & 52.5 \\
1373 & 112 & 44.8 & - & - & - & 28.0 & 50.9 \\
1473 & 109 & 43.4 & - & - & - & 27.1 & 49.3 \\
1573 & 105 & 42.0 & - & - & - & 26.3 & 47.7 \\
1673 & 101 & 40.6 & - & - & - & 25.4 & 46.1 \\
\hline
\end{tabular}

${ }^{1}$ No temperature dependence is assumed.

Table 5. Elastic properties ( $E, v$, and $G)$ of mullite layer.

\begin{tabular}{cccccccc}
\hline \multirow{2}{*}{ Temp. } & \multicolumn{2}{c}{$E[\mathrm{GPa}]$} & \multicolumn{3}{c}{$\boldsymbol{v}$} & \multicolumn{2}{c}{$G$ [GPa] } \\
\cline { 2 - 7 } $\boldsymbol{T}[\mathrm{K}]$ & $\boldsymbol{E}_{\boldsymbol{x}}$ & $\boldsymbol{E}_{\boldsymbol{y}}$ & $\boldsymbol{v}_{\boldsymbol{x} y}$ & $\boldsymbol{v}_{\boldsymbol{x} z}$ & $\boldsymbol{v}_{\boldsymbol{y} z}$ & $\boldsymbol{G}_{\boldsymbol{x} y}$ & $\boldsymbol{G}_{\boldsymbol{x} z}$ \\
\hline 303 & 103 & 214 & $0.195^{1}$ & $0.3^{1}$ & $0.405^{1}$ & 55.0 & 39.6 \\
373 & 102 & 213 & - & - & - & 54.8 & 39.4 \\
473 & 102 & 211 & - & - & - & 54.3 & 39.1 \\
573 & 101 & 209 & - & - & - & 53.8 & 38.7 \\
673 & 100 & 207 & - & - & - & 53.3 & 38.4 \\
773 & 98.9 & 205 & - & - & - & 52.8 & 38.0 \\
873 & 98.0 & 204 & - & - & - & 52.3 & 37.7 \\
\hline
\end{tabular}


Table 5. Cont.

\begin{tabular}{cccccccc}
\hline \multirow{2}{*}{ Temp. } & \multicolumn{2}{c}{$E[\mathrm{GPa}]$} & \multicolumn{2}{c}{$\boldsymbol{v}$} & \multicolumn{2}{c}{$G$ [GPa] } \\
\cline { 2 - 8 } $\boldsymbol{T}[\mathrm{K}]$ & $\boldsymbol{E}_{\boldsymbol{x}}$ & $\boldsymbol{E}_{\boldsymbol{y}}$ & $\boldsymbol{v}_{\boldsymbol{x} y}$ & $\boldsymbol{v}_{\boldsymbol{x} z}$ & $\boldsymbol{v}_{\boldsymbol{y} z}$ & $\boldsymbol{G}_{\boldsymbol{x y}}$ & $\boldsymbol{G}_{\boldsymbol{x} z}$ \\
\hline 973 & 97.0 & 202 & - & - & - & 51.8 & 37.3 \\
1073 & 96.1 & 200 & - & - & - & 51.3 & 36.9 \\
1173 & 95.1 & 198 & - & - & - & 50.8 & 36.6 \\
1273 & 94.1 & 196 & - & - & - & 50.3 & 36.2 \\
1373 & 93.2 & 194 & - & - & - & 49.8 & 35.8 \\
1473 & 92.2 & 192 & - & - & - & 49.3 & 35.5 \\
1573 & 91.2 & 190 & - & - & - & 48.8 & 35.1 \\
1673 & 90.3 & 188 & - & - & - & 48.2 & 34.7 \\
\hline
\end{tabular}

${ }^{1}$ No temperature dependence is assumed.

Table 6. Elastic properties ( $E, v$, and $G)$ of YbMS anisotropic homogenous layer.

\begin{tabular}{cccccccc}
\hline \multirow{2}{*}{ Temp. } & \multicolumn{2}{c}{$E[\mathrm{GPa}]$} & \multicolumn{2}{c}{$\boldsymbol{v}$} & \multicolumn{3}{c}{$G[\mathrm{GPa}]$} \\
\cline { 2 - 8 } $\boldsymbol{T}[\mathrm{K}]$ & $\boldsymbol{E}_{\boldsymbol{x}}$ & $\boldsymbol{E}_{\boldsymbol{y}}$ & $\boldsymbol{v}_{\boldsymbol{x} y}$ & $\boldsymbol{v}_{\boldsymbol{x} z}$ & $\boldsymbol{v}_{\boldsymbol{y z}}$ & $\boldsymbol{G}_{\boldsymbol{x} y}$ & $\boldsymbol{G}_{\boldsymbol{x} z}$ \\
\hline 303 & 0.135 & 96 & $0.003^{1}$ & $0.24^{1}$ & $0.23^{1}$ & 0.135 & 0.055 \\
373 & 0.135 & 95.9 & - & - & - & 0.135 & 0.054 \\
473 & 0.135 & 95.8 & - & - & - & 0.135 & 0.054 \\
573 & 0.135 & 95.5 & - & - & - & 0.134 & 0.054 \\
673 & 0.134 & 95.0 & - & - & - & 0.134 & 0.054 \\
773 & 0.133 & 94.5 & - & - & - & 0.133 & 0.054 \\
873 & 0.132 & 93.8 & - & - & - & 0.132 & 0.053 \\
973 & 0.131 & 93.0 & - & - & - & 0.131 & 0.053 \\
1073 & 0.130 & 92.1 & - & - & - & 0.130 & 0.052 \\
1173 & 0.129 & 91.2 & - & - & - & 0.128 & 0.052 \\
1273 & 0.127 & 90.2 & - & - & - & 0.127 & 0.051 \\
1373 & 0.126 & 89.2 & - & - & - & 0.125 & 0.051 \\
1473 & 0.124 & 88.1 & - & - & - & 0.124 & 0.050 \\
1573 & 0.122 & 86.9 & - & - & - & 0.122 & 0.049 \\
1673 & 0.121 & 85.7 & - & - & - & 0.121 & 0.049 \\
\hline
\end{tabular}

${ }^{1}$ No temperature dependence is assumed.

Table 7. Coefficients of thermal expansion (CTEs) at reference temperature of $1673 \mathrm{~K}\left(\alpha^{\prime}\right)$ of substrate and coating layers.

\begin{tabular}{|c|c|c|c|c|c|c|c|c|c|c|}
\hline \multirow{3}{*}{$\begin{array}{l}\text { Temp. } \\
T \text { [K] }\end{array}$} & \multicolumn{10}{|c|}{$\alpha^{\prime}\left[\times 10^{-6} / \mathrm{K}\right]$} \\
\hline & \multirow{2}{*}{ Sub. } & \multirow{2}{*}{ SC } & \multirow{2}{*}{ SA } & \multirow{2}{*}{$\mathbf{M u}$} & \multicolumn{5}{|c|}{ YbDS:YbMS } & \multirow{2}{*}{ Ani } \\
\hline & & & & & $100: 0$ & $80: 20$ & $50: 50$ & $20: 80$ & $0: 100$ & \\
\hline 323 & 5.10 & 4.99 & 3.61 & 6.25 & 4.62 & 4.75 & 4.96 & 5.20 & 5.39 & 5.39 \\
\hline 373 & 5.16 & 5.05 & 3.68 & 6.34 & 4.72 & 4.85 & 5.07 & 5.34 & 5.54 & 5.54 \\
\hline 473 & 5.28 & 5.17 & 3.81 & 6.50 & 4.90 & 5.05 & 5.31 & 5.61 & 5.84 & 5.84 \\
\hline 573 & 5.40 & 5.28 & 3.92 & 6.67 & 5.09 & 5.26 & 5.54 & 5.88 & 6.14 & 6.14 \\
\hline 673 & 5.51 & 5.37 & 4.02 & 6.84 & 5.27 & 5.46 & 5.78 & 6.15 & 6.44 & 6.44 \\
\hline 773 & 5.63 & 5.48 & 4.10 & 7.01 & 5.46 & 5.66 & 6.01 & 6.42 & 6.74 & 6.74 \\
\hline 873 & 5.75 & 5.53 & 4.15 & 7.18 & 5.65 & 5.87 & 6.25 & 6.70 & 7.04 & 7.04 \\
\hline 973 & 5.86 & 5.63 & 4.25 & 7.35 & 5.83 & 6.07 & 6.48 & 6.97 & 7.34 & 7.34 \\
\hline 1073 & 5.98 & 5.73 & 4.35 & 7.52 & 6.02 & 6.28 & 6.72 & 7.24 & 7.64 & 7.64 \\
\hline 1173 & 6.10 & 5.83 & 4.45 & 7.69 & 6.20 & 6.48 & 6.96 & 7.51 & 7.94 & 7.94 \\
\hline 1273 & 6.21 & 5.93 & 4.55 & 7.86 & 6.39 & 6.69 & 7.19 & 7.78 & 8.24 & 8.24 \\
\hline 1373 & 6.33 & 6.03 & 4.65 & 8.03 & 6.57 & 6.89 & 7.43 & 8.05 & 8.54 & 8.54 \\
\hline 1473 & 6.45 & 6.13 & 4.75 & 8.20 & 6.76 & 7.09 & 7.66 & 8.33 & 8.84 & 8.84 \\
\hline 1573 & 6.56 & 6.23 & 4.85 & 8.37 & 6.95 & 7.30 & 7.89 & 8.60 & 9.14 & 9.14 \\
\hline 1693 & 6.70 & 6.35 & 4.97 & 8.57 & 7.17 & 7.54 & 8.18 & 8.92 & 9.50 & 9.50 \\
\hline
\end{tabular}


Table 8. Creep properties ( $C$ and $n$ ) of coating layers.

\begin{tabular}{|c|c|c|c|c|c|c|c|c|}
\hline \multirow{3}{*}{$\begin{array}{l}\text { Temp. } \\
T \text { [K] }\end{array}$} & \multicolumn{8}{|c|}{$C^{1}$} \\
\hline & \multirow{2}{*}{ SA } & \multirow{2}{*}{$\mathbf{M u}$} & \multicolumn{5}{|c|}{ YbDS:YbMS } & \multirow{2}{*}{ Ani. } \\
\hline & & & 100:0 & $80: 20$ & $50: 50$ & $20: 80$ & 0:100 & \\
\hline 1173 & $2.62 \times 10^{-15}$ & $2.66 \times 10^{-20}$ & $2.26 \times 10^{-12}$ & $1.95 \times 10^{-12}$ & $1.57 \times 10^{-12}$ & $1.27 \times 10^{-12}$ & $1.10 \times 10^{-12}$ & $1.10 \times 10^{-12}$ \\
\hline 1223 & $2.42 \times 10^{-14}$ & $9.45 \times 10^{-19}$ & $1.25 \times 10^{-11}$ & $1.10 \times 10^{-11}$ & $9.08 \times 10^{-12}$ & $7.50 \times 10^{-12}$ & $6.60 \times 10^{-12}$ & $6.60 \times 10^{-12}$ \\
\hline 1273 & $1.88 \times 10^{-13}$ & $2.53 \times 10^{-17}$ & $6.05 \times 10^{-11}$ & $5.41 \times 10^{-11}$ & $4.57 \times 10^{-11}$ & $3.86 \times 10^{-11}$ & $3.44 \times 10^{-11}$ & $3.44 \times 10^{-11}$ \\
\hline 1323 & $1.25 \times 10^{-12}$ & $5.29 \times 10^{-16}$ & $2.60 \times 10^{-10}$ & $2.35 \times 10^{-10}$ & $2.03 \times 10^{-10}$ & $1.75 \times 10^{-10}$ & $1.59 \times 10^{-10}$ & $1.59 \times 10^{-10}$ \\
\hline 1373 & $7.24 \times 10^{-12}$ & $8.85 \times 10^{-15}$ & $1.00 \times 10^{-9}$ & $9.22 \times 10^{-10}$ & $8.10 \times 10^{-10}$ & $7.13 \times 10^{-10}$ & $6.54 \times 10^{-10}$ & $6.54 \times 10^{-10}$ \\
\hline 1423 & $3.71 \times 10^{-11}$ & $1.22 \times 10^{-13}$ & $3.53 \times 10^{-9}$ & $3.28 \times 10^{-9}$ & $2.93 \times 10^{-9}$ & $2.63 \times 10^{-9}$ & $2.44 \times 10^{-9}$ & $2.44 \times 10^{-9}$ \\
\hline 1473 & $1.70 \times 10^{-10}$ & $1.40 \times 10^{-12}$ & $1.14 \times 10^{-8}$ & $1.07 \times 10^{-8}$ & $9.73 \times 10^{-9}$ & $8.86 \times 10^{-9}$ & $8.32 \times 10^{-9}$ & $8.32 \times 10^{-9}$ \\
\hline 1523 & $7.04 \times 10^{-10}$ & $1.37 \times 10^{-11}$ & $3.40 \times 10^{-8}$ & $3.23 \times 10^{-8}$ & $2.99 \times 10^{-8}$ & $2.76 \times 10^{-8}$ & $2.62 \times 10^{-8}$ & $2.62 \times 10^{-8}$ \\
\hline 1573 & $2.67 \times 10^{-9}$ & $1.16 \times 10^{-10}$ & $9.48 \times 10^{-8}$ & $9.08 \times 10^{-8}$ & $8.53 \times 10^{-8}$ & $8.00 \times 10^{-8}$ & $7.67 \times 10^{-8}$ & $7.67 \times 10^{-8}$ \\
\hline 1623 & $9.31 \times 10^{-9}$ & $8.61 \times 10^{-10}$ & $2.48 \times 10^{-7}$ & $2.40 \times 10^{-7}$ & $2.28 \times 10^{-7}$ & $2.17 \times 10^{-7}$ & $2.10 \times 10^{-7}$ & $2.10 \times 10^{-7}$ \\
\hline 1673 & $3.01 \times 10^{-8}$ & $5.67 \times 10^{-9}$ & $6.12 \times 10^{-7}$ & $5.98 \times 10^{-7}$ & $5.76 \times 10^{-7}$ & $5.55 \times 10^{-7}$ & $5.42 \times 10^{-7}$ & $5.42 \times 10^{-7}$ \\
\hline \multirow{4}{*}{ - } & \multicolumn{8}{|c|}{$n^{2}$} \\
\hline & \multirow{2}{*}{ SA } & \multirow{2}{*}{ Mu } & \multicolumn{5}{|c|}{ YbDS:YbMS } & \multirow{2}{*}{ Ani. } \\
\hline & & & 100:0 & $80: 20$ & $50: 50$ & $20: 80$ & 0:100 & \\
\hline & 1.09 & 1.20 & 0.960 & 0.976 & 1.00 & 1.02 & 1.04 & 1.04 \\
\hline
\end{tabular}

${ }^{1}$ The unit of $C$ depends on the corresponding creep index $n .{ }^{2}$ No temperature dependence is assumed.

\subsubsection{Interface Crack Introduction Analysis}

ERR owing to the thermal stress, $\mathcal{G}^{\text {th }}$, is defined as the reduction in strain energy, $\Pi$, stored in a structure per increased crack area. When the crack area, $A$, increases to $A+\mathrm{d} A$, ERR is evaluated as follows:

$$
\mathcal{G}^{\text {th }}=-\frac{\mathrm{d} \Pi}{\mathrm{d} A}
$$

Thus, it is necessary to obtain the strain energies stored in T/EBC with different crack lengths to evaluate $\mathcal{G}_{\text {init }}^{\text {th }}\left(=\left.\mathcal{G}^{\text {th }}\right|_{A \rightarrow 0}\right)$ and $\mathcal{G}_{\text {prop. }}^{\text {th }}$. We carried out FEM analyses for T/EBC models with various crack length under the stress condition obtained from the thermal stress analysis, and the strain energy in T/EBC was evaluated as a function of crack length.

The geometry, the boundary conditions and the mesh sizes of the model in this analysis were set in the same way as in the thermal stress analysis. The initial stress condition was derived from the stress distribution of the uncracked T/EBC model obtained by the thermal stress analysis. The temperature was kept constant at $303 \mathrm{~K}$ (temperature after the cooling process) during the analyses, and thus we used the material properties $E$ and $v$ at $303 \mathrm{~K}$ shown in Tables 2-6. Interface cracks were introduced from the right edge of the simulation model shown in Figure 2. According to a preliminary FEM analysis, the $\mathrm{SiC} / \mathrm{SiAlON}$, SiAlON/mullite and mullite/YbDS interfaces were chosen as the objective interfaces to evaluate $\mathcal{G}_{\text {init }}^{\text {th }}$ and $\mathcal{G}_{\text {prop }}^{\text {th }}$ (the detail of the preliminary analysis is found in Appendix B).

\subsubsection{Evaluation of ERR for Interface Crack Initiation and Propagation}

We evaluated $\mathcal{G}_{\text {init }}^{\text {th }}$ and $\mathcal{G}_{\text {prop }}^{\text {th }}$ from the strain energy in T/EBC with different crack lengths obtained by the FEM analyses in Section 2.2.3 in the following ways.

Evaluation of $\mathcal{G}_{\text {init }}^{\text {th }}$

$\mathcal{G}_{\text {init }}^{\text {th }}$ is defined as ERR in the limit when $A$ approaches 0, as follows:

$$
\mathcal{G}_{\text {init }}^{\text {th }}=-\lim _{A \rightarrow 0} \frac{\mathrm{d} \Pi}{\mathrm{d} A} \text {. }
$$

Note that $\mathcal{G}_{\text {init }}^{\text {th }}$ is equal to the first-order coefficient of the Taylor expansion of $\Pi(A)$ around $A=0$ with the inverted sign. Therefore, we approximated $\Pi(A)$ as a polynomial from the FEM analyses for the T/EBC models with several different crack lengths, and $\mathcal{G}_{\text {init }}^{\text {th }}$ was evaluated as the first-order 
coefficient of the polynomial with the inverted sign. Two cases are possible according to the sign of $\mathcal{G}_{\text {init }}^{\text {th }}$ : for $\mathcal{G}_{\text {init }}^{\text {th }}>0$, crack initiation occurs if the interface fracture toughness, $\Gamma$, is smaller than $\mathcal{G}_{\text {init }}^{\text {th }}$; for $\mathcal{G}_{\text {init }}^{\text {th }}<0$, no crack initiation is expected. From the result of the preliminary analysis (Appendix B), we examined crack length $a=2.5,5.0$ and $7.5 \mu \mathrm{m}$ to evaluate $\mathcal{G}_{\text {init }}^{\text {th }}$ at the objective interfaces.

Evaluation of $\mathcal{G}_{\text {prop }}^{\text {th }}$

ERR when a crack propagates from $A$ to $A+\Delta A$ is given by numerical differentiation as follows:

$$
\mathcal{G}_{\text {prop }}^{\text {th }}\left(A+\frac{\Delta A}{2}\right)=-\left.\frac{\mathrm{d} \Pi}{\mathrm{d} A}\right|_{A+\Delta A / 2} \approx-\frac{\Pi(A+\Delta A)-\Pi(A)}{\Delta A} .
$$

From the result of the preliminary analysis (Appendix B), the $a$ for evaluation of $\mathcal{G}_{\text {prop }}^{\text {th }}$ was determined as 2.5, 5.0, 7.5, 10, 50, 100, 250, .., $3500 \mu \mathrm{m}$ in increments of $250 \mu \mathrm{m}$ between 250 and $3500 \mu \mathrm{m}$.

\subsection{Interface Fracture Test}

Interfacial toughness was measured by an interface fracture test. The test method was a modification of the one designed for $\mathrm{EBCs}$ on $\mathrm{SiC} / \mathrm{SiC}$ composites having a weak inter-laminar strength [16]. Figure 3 shows schematic of the test set-up.

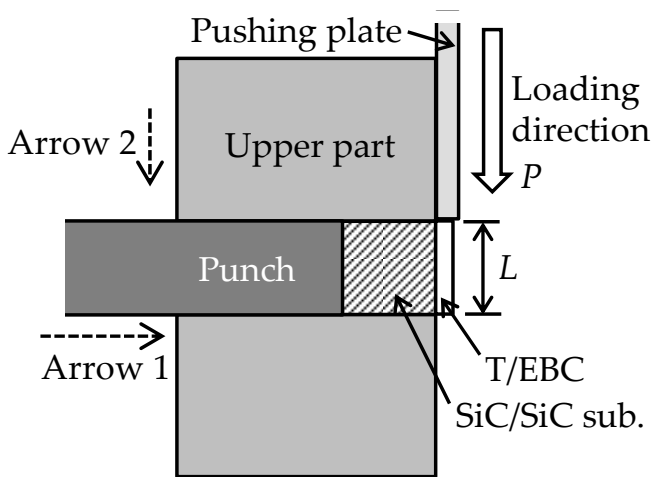

(a)

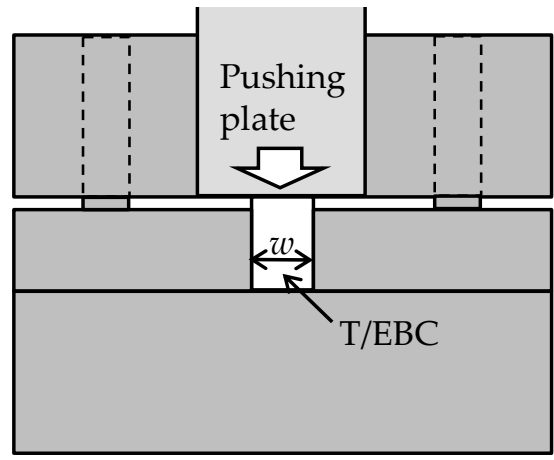

(b)

Figure 3. Schematics of experimental set-up of interface fracture test: (a) Cross-sectional side view; (b) Front view.

A block of specimen with a height, $L$, of $4 \mathrm{~mm}$ and a width, $w$, of $3 \mathrm{~mm}$ was prepared using a diamond blade saw in such a way that one of the fiber directions in the woven fabric of the $\mathrm{SiC} / \mathrm{SiC}$ substrate was oriented to the longitudinal side of the specimen. The surface was as cut without polishing to avoid the coating delamination during the processing. The cut surface was smooth enough for us to distinguish the interface in the cross-sectional observation by conventional optical microscopy.

The specimen was set in a steel jig like a horizontal die, the upper part of which was adjustable. The specimen was put in the die and slid horizontally from the back side by a punch as indicated by the dashed arrow 1 in Figure 3 so that only the coating protruded from the die while the substrate was buried. Then the upper part was adjusted in the vertical direction (the dashed arrow 2 in Figure 3) to fix the specimen. The jig with the fixed specimen was placed under a universal testing machine (load cell capacity: 500 N, EZ-LX, Shimadzu Corporation, Kyoto, Japan) having a steel pushing plate with a thickness of $0.5 \mathrm{~mm}$ and a width of $5 \mathrm{~mm}$.

The edge of the coating was compressively loaded by the plate with a constant crosshead speed of $0.024 \mathrm{~mm} / \mathrm{min}$ till the coating was delaminated from the substrate; thus, the mode II-rich loading at the interface was achieved with little loading to the substrate in the inter-laminar shear direction. The shear stress ought not to concentrate at only an interface between $\mathrm{SiC} / \mathrm{SiC}$ substrate and T/EBC 
( $\mathrm{SiC} / \mathrm{SiAlON}$ interface); i.e., it occurs along some interfaces in T/EBC. The pushing load, $P$, and the crosshead displacement, $u$, were measured during the test. The coating near the loading point was observed in the cross-sectional direction of the specimen by optical microscopy to determine when a crack was initiated at the loaded edge and the corresponding load, $P_{\text {init }}$. The number of the tests was six.

The energy release rate, $\mathcal{G}_{\text {init }}$, associated with the initiation of an interface crack at the loaded edge under an applied load of $P_{\text {init }}$ is given by

$$
\mathcal{G}_{\text {init }}=\frac{\left(P_{\text {init }}\right)^{2}}{2 w^{2} h_{\text {coat }}}\left\{\frac{1}{E_{\text {coat }}^{\prime}}-\frac{1}{E_{\text {sub }}^{\prime}}\left(\frac{1}{D}+\frac{\left(h_{\text {coat }} / 2+h_{\text {sub }}-\delta\right)^{2}}{I\left(h_{\text {coat }}\right)^{2}}\right)\right\} .
$$

Definition of parameters and details of deriving Equation (4) are shown in Appendix C. The $\mathcal{G}_{\text {init }}$ is defined as fracture toughness for the interface crack initiation, $\Gamma_{\text {init }}$. Note that, $\Gamma_{\text {init }}$ is a nominal fracture toughness value of interface crack initiation including the effect of thermal residual stress.

After the tests, four of the specimens were mounted in resin and their cross-sections of the delaminated coating and substrate were observed; the cross-section was polished to mirror finish. SEM observation (VE-7800, Keyence corporation, Osaka, Japan) and energy dispersive X-ray (EDX) analysis (EX74120 attached to field emission SEM (JSM6500F, JEOL Ltd., Tokyo, Japan)) of the cross section were done to identify the fractured interface. The remaining two specimens were served for the analyses of fracture surfaces; optical and SEM observations and EDX analysis were done.

\section{Results of T/EBC Fabrication}

\subsection{Layer Thickness Condition for Preventing the Objective Interface Crack Initiation}

Figure $4 \mathrm{a}-\mathrm{c}$ show the relationships between the SiAlON layer thickness, $h_{\mathrm{SA}}$, and $\mathcal{G}_{\text {init }}^{\text {th }}$ at the $\mathrm{SiC} / \mathrm{SiAlON}, \mathrm{SiAlON} /$ mullite and mullite/YbDS interfaces, respectively, with various mullite layer thicknesses, $h_{\mathrm{Mu}}$. From Figure $4 \mathrm{a}$, the ERR for interface crack initiation at the SiC/SiAlON interface, $\mathcal{G}_{\text {init, SC/SA }}^{\text {th }}$ is nearly zero for any combination of layer thicknesses. Thus, a crack is unlikely to initiate at the SiC/SiAlON interface during the cooling process after deposition if thicknesses of the SiAlON and mullite layers are both within the range of $5-25 \mu \mathrm{m}$.

The ERR for interface crack initiation at the SiAlON/mullite interface, $\mathcal{G}_{\text {init, }}^{\text {th }} \mathrm{SA} / \mathrm{Mu}^{\prime}$ depends on the thicknesses of $h_{\mathrm{SA}}$ and $h_{\mathrm{Mu}}$ as shown in Figure $4 \mathrm{~b}$, which is found to be expressed as the following equation within the examined range of $h_{\mathrm{SA}}$ and $h_{\mathrm{Mu}}(5-25 \mu \mathrm{m})$ :

$$
\mathcal{G}_{\text {init,SA } / \mathrm{Mu}}^{\mathrm{th}}\left(h_{\mathrm{SA}}, h_{\mathrm{Mu}}\right)=\sum_{k=0}^{2} \sum_{l=0}^{2} c_{k l}\left(h_{\mathrm{SA}}\right)^{k}\left(h_{\mathrm{Mu}}\right)^{l}
$$

with the coefficients, $c_{k l}$, listed in Table 9. Figure 5 shows the contour chart of $\mathcal{G}_{\text {init, }}^{\text {th }}$ A $/ \mathrm{Mu}$ as a function of $h_{\mathrm{SA}}$ and $h_{\mathrm{Mu}}$ shown in Equation (5). The level of $\mathcal{G}_{\text {init, } \mathrm{SA} / \mathrm{Mu}}^{\text {th }}$ is indicated by the depth of color (violet); a deeper-colored region corresponds to a lower $\mathcal{G}_{\text {init, } \mathrm{SA} / \mathrm{Mu}}^{\text {th }}$ and thus a better combination of layer thicknesses. This result suggests that one of the SiAlON or mullite layers must be thick and the other be thin in order to decrease $\mathcal{G}_{\text {init, } \mathrm{SA} / \mathrm{Mu}}^{\text {th }}$ and hinder crack initiation at the SiAlON/mullite interface. 


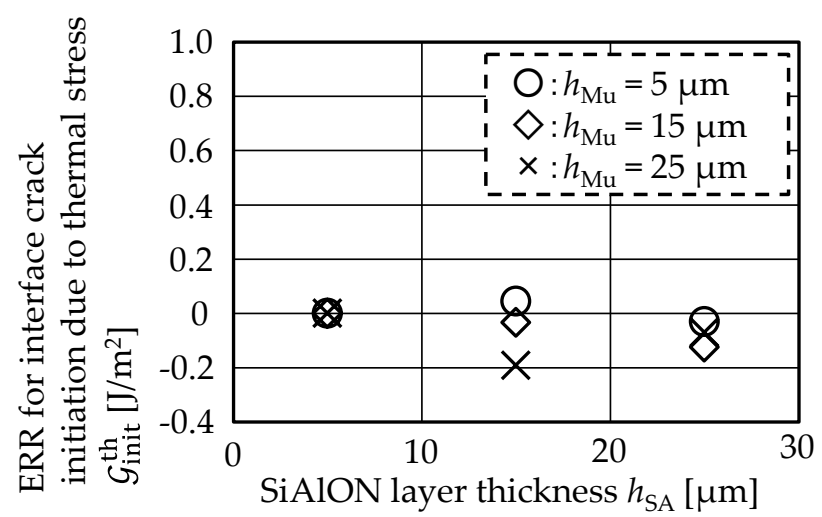

(a)

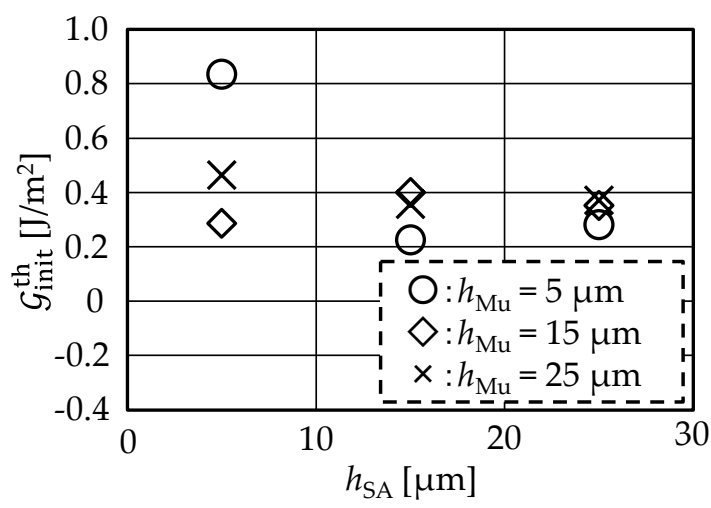

(b)

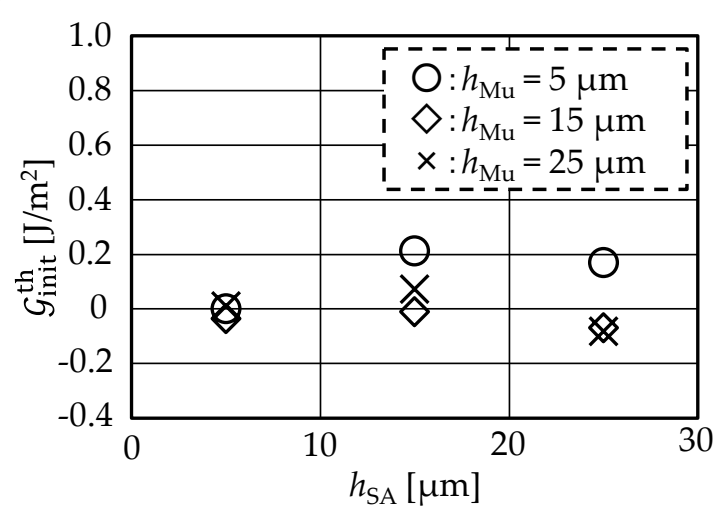

(c)

Figure 4. Relationship between SiAlON layer thickness and ERR for interface crack initiation due to thermal stress at (a) SiC/SiAlON, (b) SiAlON/mullite and (c) mullite/YbDS interfaces with various mullite layer thicknesses.

Table 9. Coefficients for polynomial approximation of $\mathcal{G}_{\mathrm{init}, \mathrm{SA} / \mathrm{Mu}}^{\mathrm{th}}\left(h_{\mathrm{SA}}, h_{\mathrm{Mu}}\right)$ in Equation $(5), c_{k l}{ }^{1}$.

\begin{tabular}{ccccc}
\hline & \multirow{2}{*}{$c_{k l}$} & & \multicolumn{3}{c}{$\boldsymbol{l}$} \\
\cline { 3 - 5 } & & $\mathbf{0}$ & $\mathbf{1}$ & $\mathbf{2}$ \\
\hline \multirow{3}{*}{$k$} & $\mathbf{0}$ & 2.61 & $-2.83 \times 10^{-1}$ & $8.06 \times 10^{-3}$ \\
& $\mathbf{1}$ & $-2.82 \times 10^{-1}$ & $3.60 \times 10^{-2}$ & $-1.03 \times 10^{-3}$ \\
& $\mathbf{2}$ & $7.48 \times 10^{-3}$ & $-9.68 \times 10^{-4}$ & $2.77 \times 10^{-5}$ \\
\hline \multicolumn{4}{c}{${ }^{1}$ Unit of $c_{k l}: \mu \mathrm{m}^{(k+l)}}$.
\end{tabular}

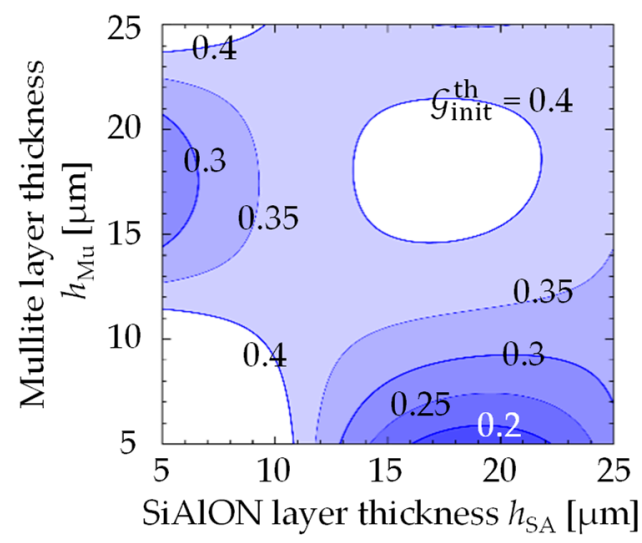

Figure 5. Contour chart of $\mathcal{G}_{\text {init,SA/Mu }}^{\text {th }}\left(h_{\mathrm{SA}}, h_{\mathrm{Mu}}\right)$ interpolated with Equation (5). 
As shown in Figure $4 c$, it is found that a thin mullite layer $\left(h_{\mathrm{Mu}}=5 \mu \mathrm{m}\right)$ results in a rise in the ERR for interface crack initiation at the mullite/YbDS interface, $\mathcal{G}_{\text {init, } \mathrm{Mu} / \mathrm{YD}^{\prime}}^{\text {th }}$ with increasing $h_{\mathrm{SA}}$, while a thicker mullite layer $\left(h_{\mathrm{Mu}}=15\right.$ and $\left.25 \mu \mathrm{m}\right)$ reduces $\mathcal{G}_{\text {init, Mu/YD }}^{\text {th }}$ to almost zero regardless of $h_{\mathrm{SA}}$. Therefore, a thick mullite layer is necessary to decrease $\mathcal{G}_{\text {init, } \mathrm{Mu} / \mathrm{YD}^{\prime}}$ i.e., to suppress crack initiation at the mullite/YbDS interface.

From the above results, it is found that a thin SiAlON layer and a thick mullite layer are required for reducing $\mathcal{G}_{\text {init }}^{\text {th }}$ and preventing crack initiation at the SiC/SiAlON, SiAlON/mullite and mullite/YbDS interfaces, where strong stress concentration is expected during the cooling process in fabrication of T/EBC as shown in Figure 1.

\subsection{Phase Structure of $T / E B C$}

In Section 3.1, we found that thinning the SiAlON layer together with thickening the mullite layer was effective in suppressing interface crack formation during cooling where a large thermal stress is expected, i.e., the $\mathrm{SiC} / \mathrm{SiAlON}, \mathrm{SiAlON} /$ mullite and mullite/YbDS interfaces. In this study, therefore, the thickness of the SiAlON layer and the mullite layer were determined to be 5 and $20 \mu \mathrm{m}$, respectively, and T/EBC was prepared by the dual EB-PVD process described in Section 2.1. We confirmed no delamination at all the interfaces of the fabricated T/EBC. Cross-sectional SEM images and elemental mapping images of T/EBC were shown in Figure $6 a, b$, respectively, where we found the thicknesses of constituent layers to be; SiAlON: about $5 \mu \mathrm{m}$, mullite: about $20 \mu \mathrm{m}$, Yb-silicate gradient composition layer: about $100 \mu \mathrm{m}$, and porous segmented YbMS layer: about $200 \mu \mathrm{m}$. That is, T/EBC was successfully fabricated nearly as designed.

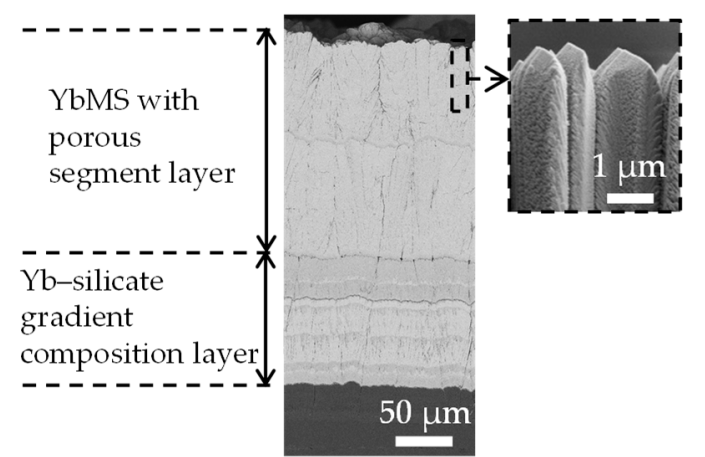

(a)

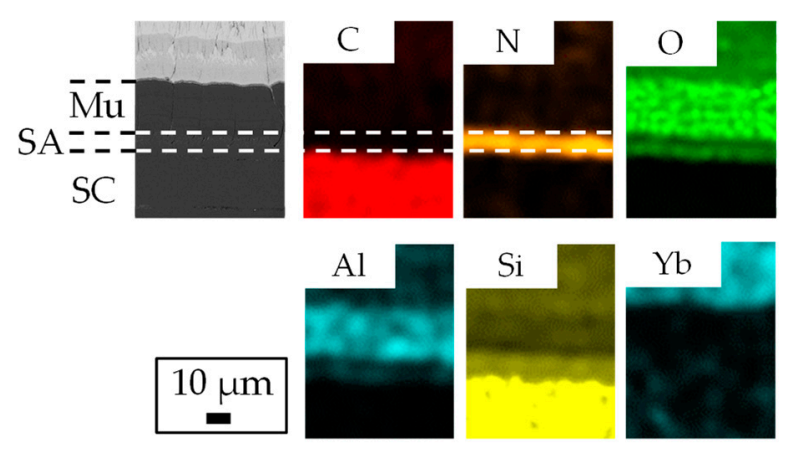

(b)

Figure 6. (a) Cross-sectional SEM images of T/EBC and (b) elemental mapping images focused on $\mathrm{SiC} / \mathrm{SiAlON} /$ mullite layers.

\section{Behavior of Interface Crack Initiation and Propagation in T/EBC}

To investigate the behavior of crack initiation and propagation during the cooling process in fabrication of T/EBC shown in Section 3.2, calculated ERRs $\left(\mathcal{G}_{\text {init }^{\prime}}^{\text {th }} \mathcal{G}_{\text {prop }}^{\text {th }}\right)$ must be compared with interface fracture toughness obtained by experiment. Thus, we carried out the interface fracture toughness tests (Section 2.3) to obtain $\Gamma$, which is to be compared with $\mathcal{G}_{\text {init }}^{\text {th }}$ and $\mathcal{G}_{\text {prop }}^{\text {th }}$ with $h_{\mathrm{SA}}=5 \mu \mathrm{m}$ and $h_{\mathrm{Mu}}=20 \mu \mathrm{m}$.

\section{1. $\mathcal{G}_{\text {init }}^{\text {th }}$ and $\mathcal{G}_{\text {prop }}^{\text {th }}$ for Objective Interface Cracks in Fabricated T/EBC}

Table 10 lists $\mathcal{G}_{\text {init }}^{\text {th }}$ of the objective interface cracks for the T/EBC model with $h_{\mathrm{SA}}=5 \mu \mathrm{m}$ and $h_{\mathrm{Mu}}$ $=20 \mu \mathrm{m}$. From this result, the $\mathrm{SiAlON} /$ mullite interface is found to possess the highest $\mathcal{G}_{\text {init }}^{\text {th }}$ of the objective interfaces. 
Table 10. $\mathcal{G}_{\text {init }}^{\text {th }}$ for T/EBC model with $h_{\mathrm{SA}}=5 \mu \mathrm{m}$ and $h_{\mathrm{Mu}}=20 \mu \mathrm{m}$.

\begin{tabular}{cc}
\hline Interface & $\mathcal{G}_{\text {init }}^{\text {th }}\left[\mathbf{J} / \mathbf{m}^{2}\right]$ \\
\hline SiC/SiAlON & 0 \\
SiAlON/mullite & 0.324 \\
Mullite/YbDS & -0.069 \\
\hline
\end{tabular}

Figure 7 shows the relationships between $\mathcal{G}_{\text {prop }}^{\text {th }}$ and $a$ at the objective interfaces in the T/EBC with $h_{\mathrm{SA}}=5 \mu \mathrm{m}$ and $h_{\mathrm{Mu}}=20 \mu \mathrm{m}$. In the $\mathcal{G}_{\text {prop }}^{\text {th }}-a$ relationships at all the objective interfaces, we observe three stages with increasing $a$ : (A) $\mathcal{G}_{\text {prop }}^{\text {th }}$ shows a relatively rapid increase; (B) $\mathcal{G}_{\text {prop }}^{\text {th }}$ decreases; (C) $\mathcal{G}_{\text {prop }}^{\text {th }}$ increases again.

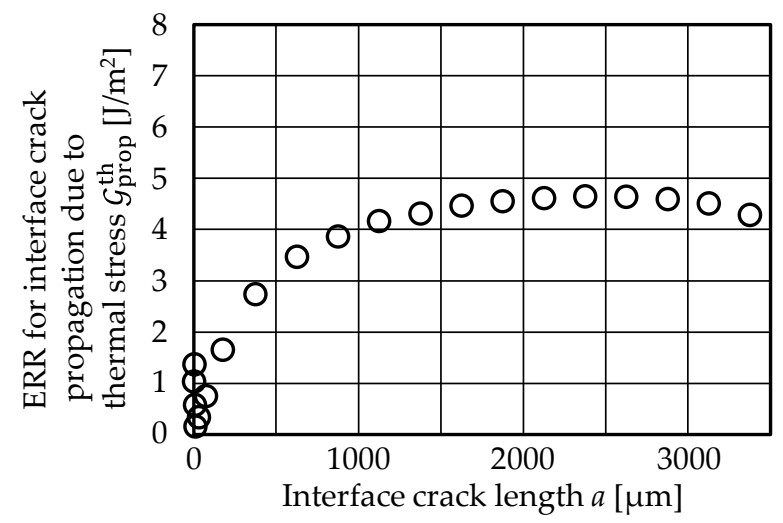

(a-1)

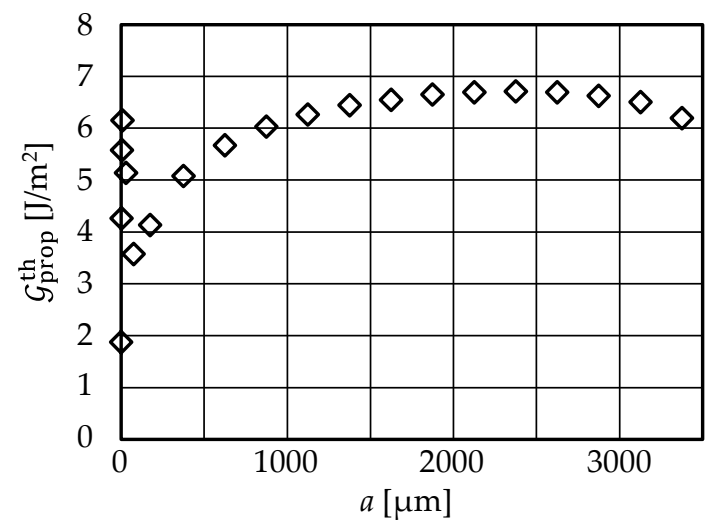

(b-1)

(a)

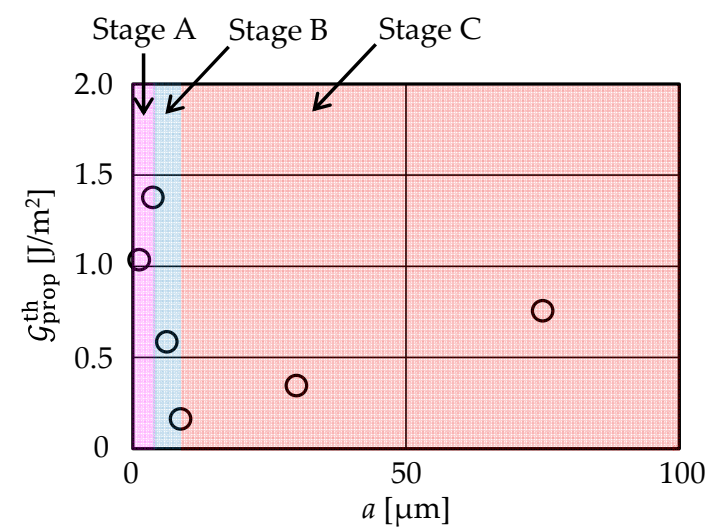

(a-2)

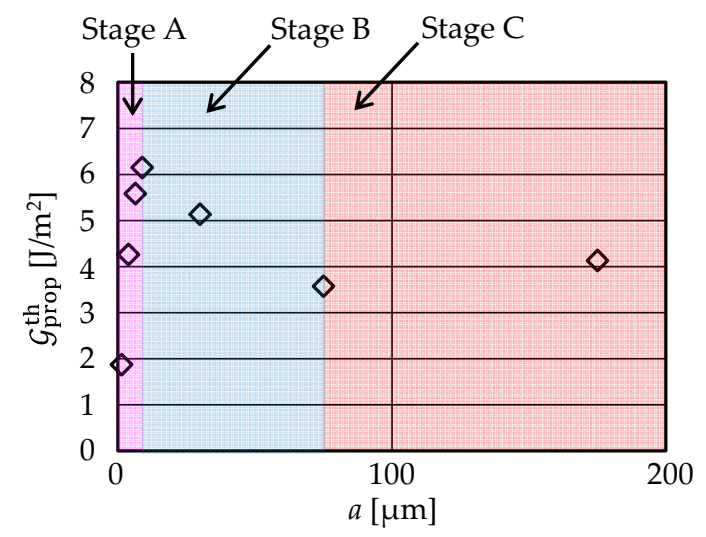

(b-2)

(b)

Figure 7. Cont. 


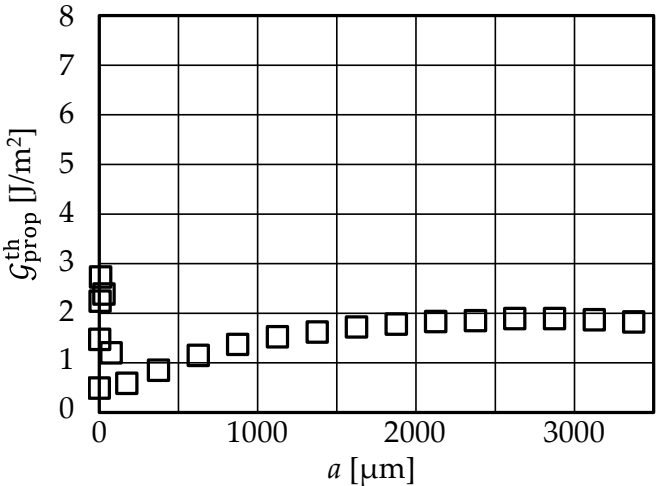

(c-1)

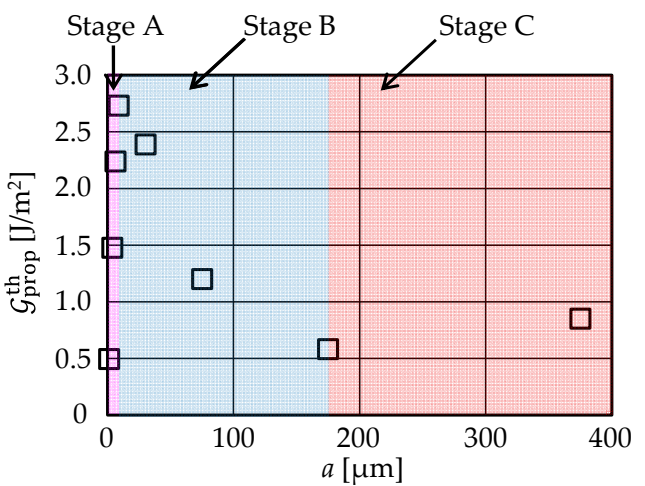

$(c-2)$

(c)

Figure 7. Relationships between ERR for interface crack propagation due to the thermal stress and crack length at objective interfaces in T/EBC with $h_{\mathrm{SA}}=5 \mu \mathrm{m}$ and $h_{\mathrm{Mu}}=20 \mu \mathrm{m}$; (a) SiC/SiAlON interface: (a-1) $0 \leq a \leq 3500 \mu \mathrm{m}$ and (a-2) $0 \leq \mathrm{a} \leq 100 \mu \mathrm{m}$, (b) SiAlON/mullite interface: (b-1) $0 \leq \mathrm{a} \leq 3500 \mu \mathrm{m}$ and (b-2) $0 \leq \mathrm{a} \leq 200 \mu \mathrm{m}$ and (c) mullite/YbDS interface: (c-1) $0 \leq \mathrm{a} \leq 3500 \mu \mathrm{m}$ and (c-2) $0 \leq \mathrm{a} \leq 100 \mu \mathrm{m}$.

The reason for the decrease in $\mathcal{G}_{\text {prop }}^{\text {th }}$ at Stage B is explained by the distribution of out-of-plane thermal stress in the vicinity of the interface edge. Figure 8a shows the $\sigma_{y}$ distributions in the coating layers along the $y$ axis, which are obtained at the positions $r_{x}$ distant from the right interface edge in the $x$ direction $\left(r_{x}=0,5,10,20,30\right.$ and $\left.40 \mu \mathrm{m}\right)$. The highest level of $\sigma_{y}$ was observed at the interface edge $\left(r_{x}\right.$ $=0 \mu \mathrm{m})$, and the $\sigma_{y}$ distribution reduces immediately to a negligible level within $r_{x}=30 \mu \mathrm{m}$. Thus, the effect of $\sigma_{y}$ on the coating layers is significant but extremely localized in the vicinity of interface edge, while that is negligible inside the simulation model. Note that the effect of $\sigma_{x}$ on $\mathcal{G}_{\text {prop }}^{\text {th }}$ is marginal for sufficiently small $a$ because we find $\sigma_{x} \sim 0$ at the interface edge $\left(r_{x}=0 \mu \mathrm{m}\right)$ directly from the balance of stress component in the $x$ direction. Figure $8 \mathrm{~b}$ shows the $\sigma_{x}$ distributions in the coating layers along the $y$ axis at various $r_{x}$. These results indicate that $\sigma_{y}$ has a dominating effect on $\mathcal{G}_{\text {prop }}^{\text {th }}$ for very short cracks. The mechanism of the second rise in $\mathcal{G}_{\text {prop }}^{\text {th }}$ at Stage $C$ is attributed to the increase in the level of $\sigma_{x}$ inside the simulation model as shown in Figure $8 \mathrm{~b}$. Therefore, the three-stage behavior in the $\mathcal{G}_{\text {prop }}^{\text {th }}-a$ relationship is explained as follows: in the beginning, $\mathcal{G}_{\text {prop }}^{\text {th }}$ rises as a crack propagates owing to the strong $\sigma_{y}$ near the interface edge (Stage A); then $\mathcal{G}_{\text {prop }}^{\text {th }}$ decreases because of a steep drop in $\sigma_{y}$ inside the model (Stage B); for a sufficiently long crack, $\mathcal{G}_{\text {prop }}^{\text {th }}$ is mainly affected by $\sigma_{x}$ and rises again with increasing $\sigma_{x}$ (Stage C).
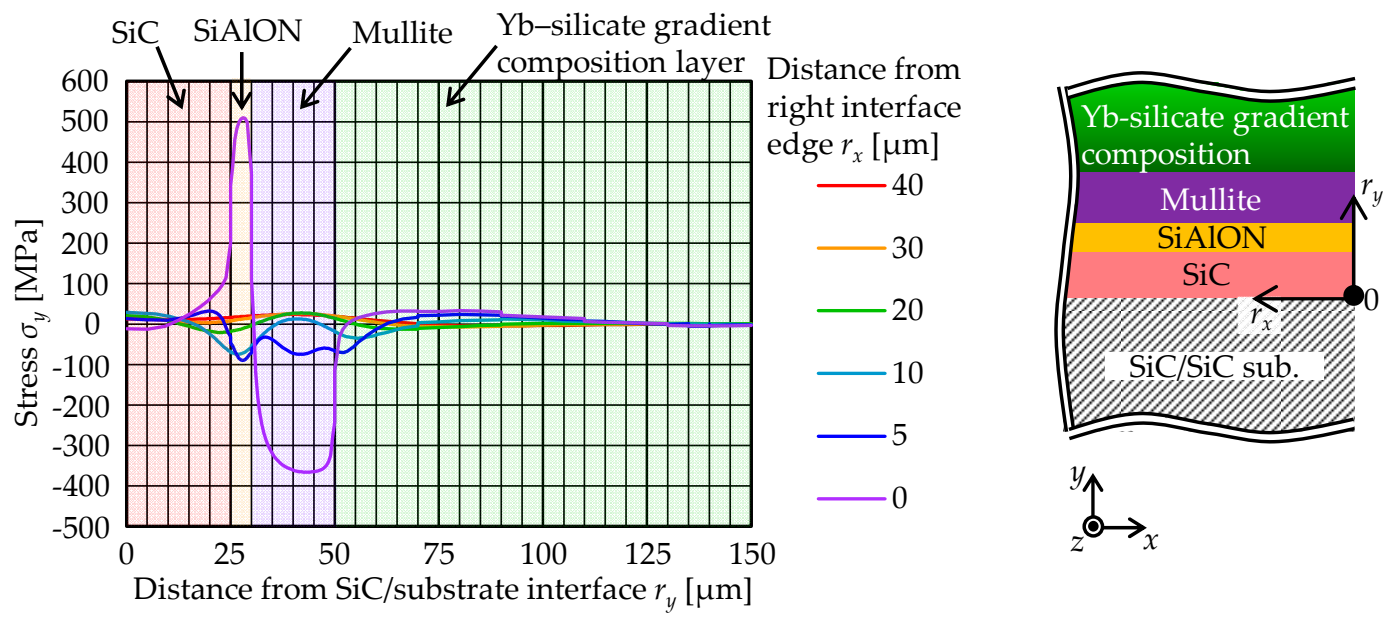

(a)

Figure 8. Cont. 


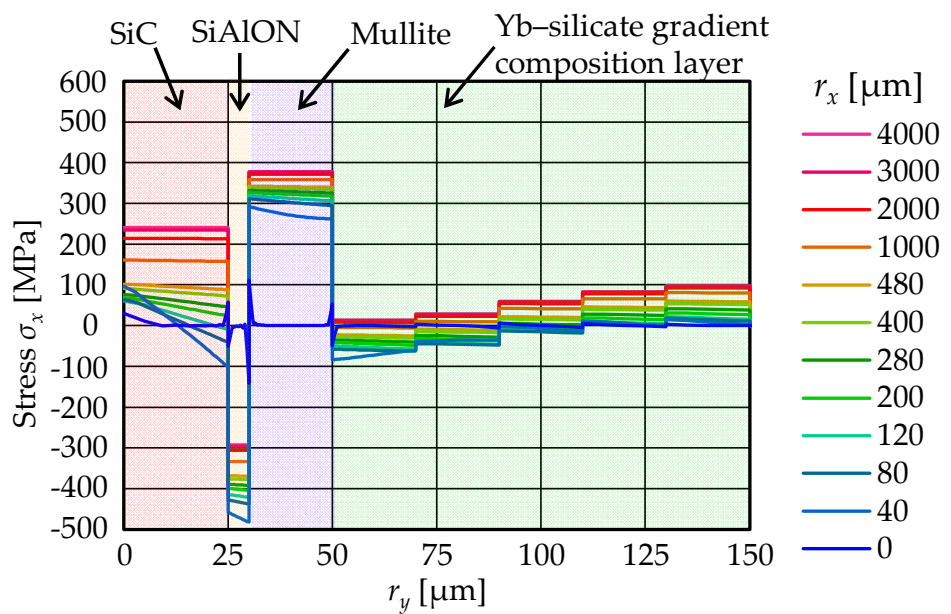

(b)

Figure 8. (a) $\sigma_{y}$ distributions, and (b) $\sigma_{x}$ distributions in coating layers along the $y$ axis at the positions $r_{x}$ distant from right $\mathrm{SiC} /$ substrate interface edge in the $x$ direction.

\subsection{Interface Fracture Toughness of T/EBC}

Figure 9 shows a typical $P-u$ curve during the tests. By the cross-sectional optical microscopy, the onset of interface fracture near the loaded edge was identified at Point $\mathrm{A}$ in $P-u$ curve before the maximum load. The load at Point A is defined as $P_{\text {init }}$. The crack then propagated down through the interface to the midway till the load reached the maximum; finally it grew unstably to the complete delamination at the maximum load. Buckling or compressive fracture of the coating was not observed during the test. The measured $P_{\text {init }}$ values for respective tests are listed in Table 11.

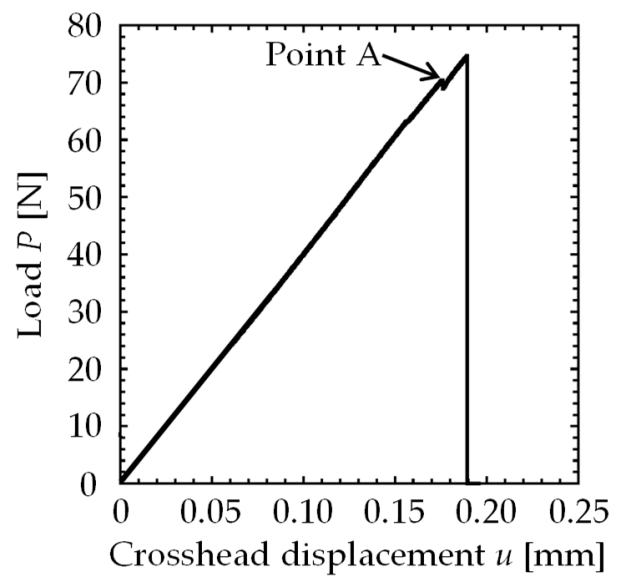

Figure 9. Typical load-crosshead displacement curve during test (Specimen No. 2).

Table 11. Crack initiation load $\left(P_{\text {init }}\right)$ obtained by interface fracture test.

\begin{tabular}{cc}
\hline Specimen Number & $\boldsymbol{P}_{\text {init }}[\mathbf{N}]$ \\
\hline 1 & 83 \\
2 & 70 \\
3 & 71 \\
4 & 64 \\
5 & 76 \\
6 & 76 \\
Average & 73 \\
\hline
\end{tabular}


Examples of the cross-sectional SEM images of the specimens after the tests were shown in Figure 10. At the loaded edge where the interface crack started to propagate, fracture occurred below or above the SiAlON layer, i.e., either at the interface between the $\mathrm{SiC}$ and SiAlON layers (Figure 10a) or at the interface between the SiAlON and mullite layers (Figure 10b). The crack path was along either of the two interfaces, and it was switched to each other by crack kinking across the SiAlON layer. However, crack propagation within a layer, such as a crack passing through the inside of layer parallel to the coating plane, was not observed.

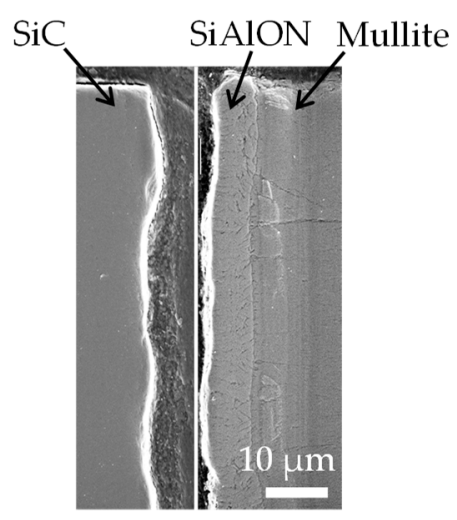

(a)

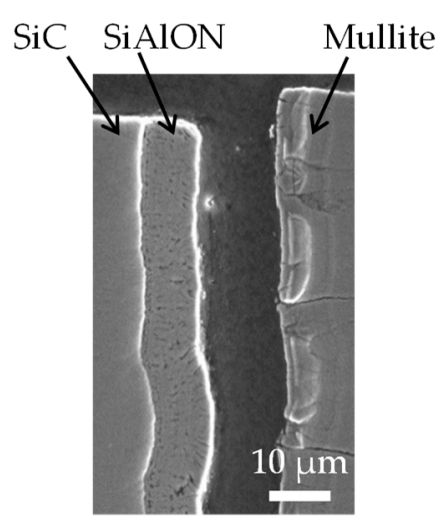

(b)

Figure 10. Examples of cross-sectional SEM images of specimens after interface fracture test; Fracture at (a) $\mathrm{SiC} / \mathrm{SiAlON}$ interface and (b) SiAlON/mullite interface.

Figure 11a shows a fracture surface near the loaded edge after the tests observed by optical microscopy. The fracture surface was classified into three according to their colors: the largest black area denoted by Region A, the gray area by Region B, and the small white area by Region C as illustrated in Figure 11a. EDX maps of a selected area in the fracture surface (indicated by a dashed rectangle in Figure 11a) are shown in Figure 11b. Mapping of element distributions shows the concentration of $\mathrm{Si}$ in Region A. In Region B the existence of $\mathrm{Si}$, $\mathrm{Al}$ and $\mathrm{N}$ was detected. Region $\mathrm{C}$ was characterized by $\mathrm{Yb}$ concentration. Apparently Al also looks rich in Region C, but it is due to misdetection because the $\mathrm{M}_{\alpha}$ line of $\mathrm{Yb}$ is very close to $\mathrm{K}_{\alpha}$ line of $\mathrm{Al}$ which was used for the mapping of $\mathrm{Al}$ distribution. These results suggest that Region A with the largest area corresponds to the fracture surface created by the interface fracture between the $\mathrm{SiC}$ and SiAlON layers observed in Figure 10a; Region B showing the second largest area corresponds to the surface created by the SiAlON/mullite interface fracture (Figure 10b). We could not observe the fractured interface corresponding to Region $C$ in the cross-sectional SEM observation of the T/EBC and substrate (Figure 10) because of the limited area of Region C. To determine the exact location of the fracture surface in Region C, we cut after the tests one of the substrate in the cross-section including Region C. The result is shown in Figure 12 suggesting that the fracture occurred in the $\mathrm{Yb}$-silicate gradient composition layer.

To calculate the line fractions of Regions A, B and C along the loaded edge, the fracture surfaces near the edge were analyzed using image processing software (Image J 1.48v, National Institute of Health, Bethesda, MD, USA) (Table 12). As shown in Table 12, fracture surface was dominantly composed of Regions A and B; the ratio of Region C was relatively small. Thus the crack initiation at the edge was supposed to occur primarily either at the interface between the $\mathrm{SiC}$ and SiAlON layers or at the interface between the SiAlON and mullite layers. 


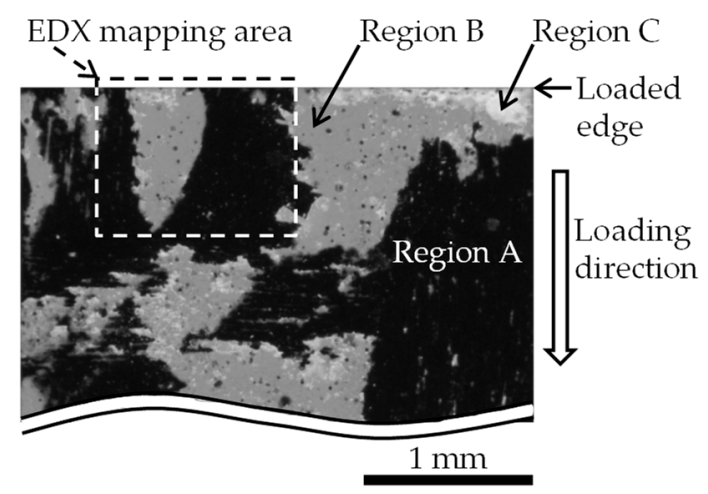

(a)

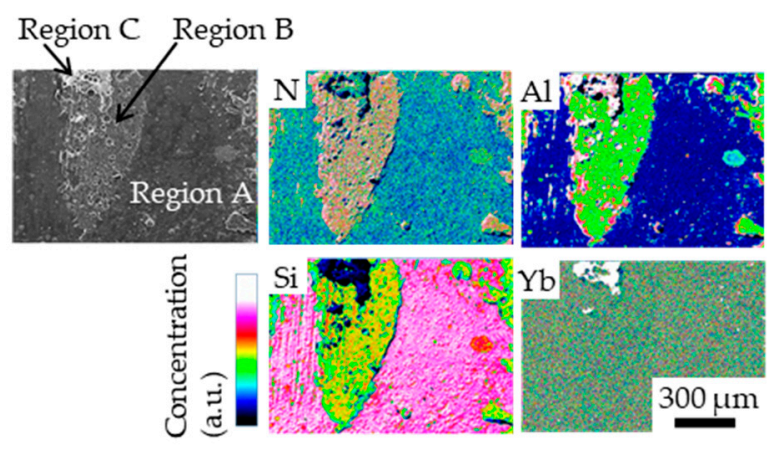

(b)

Figure 11. (a) Top view of fracture surface of specimen after interface fracture test and (b) EDX maps of selected area in fracture surface indicated by a dashed rectangle in (a).

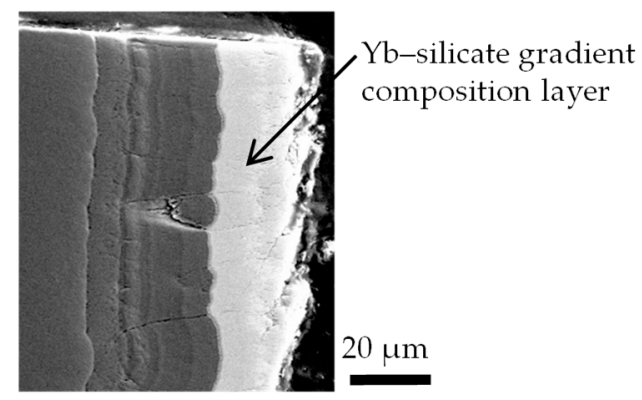

Figure 12. Cross-sectional SEM observation including Region C.

Table 12. Line fractions of Regions A, B and C at loaded edge.

\begin{tabular}{cc}
\hline Region & Line Fraction \\
\hline A & 0.31 \\
B & 0.56 \\
C & 0.13 \\
\hline
\end{tabular}

The energy release rate for the edge crack initiation along the SiC/SiAlON interface under $P_{\text {init }}$ (in Table 11) was calculated from Equations (A14)-(A18) and (4), regarding the SiC/SiC plate and the $\mathrm{SiC}$ layer as "substrate" and the rest of the layers as "coating" in Equation (A14); the mean value of $6.4 \mathrm{~J} / \mathrm{m}^{2}$ was obtained. When the SiAlON layer is counted as part of the substrate in addition to the $\mathrm{SiC} / \mathrm{SiC}$ and $\mathrm{SiC}$, the mean energy release rate for the crack along the SiAlON/mullite interface becomes $6.5 \mathrm{~J} / \mathrm{m}^{2}$. These values of energy release rates are very close to each other because the thickness of the SiAlON layer lying between the two interfaces is quite small compared to the total thickness of the system. Under the assumption that the edge crack was initiated simultaneously through the edge (i.e., in the direction of depth) at $P_{\text {init }}$ regardless of the fractured interfaces, we can estimate that the SiC/SiAlON interface fracture and the SiAlON/mullite interface fracture both occur with significant proportions at almost the same energy release rates. This suggests that the interface toughness of these two interfaces are very close; both the interfaces should have an interface toughness of $\sim 6.4 \mathrm{~J} / \mathrm{m}^{2}$. The mean energy release rate at $P_{\text {init }}$ when the edge crack was initiated along the mullite/YbDS interface, which was supposed to have large thermal stress according to the FEM analysis, was calculated to be $6.8 \mathrm{~J} / \mathrm{m}^{2}$. Since no fracture occurred at this interface at $P_{\text {init }}$, we can expect that the toughness of the interface should be larger than $6.8 \mathrm{~J} / \mathrm{m}^{2}$. The abovementioned results indicate that the approximate $\Gamma_{\text {init }}$ for the $\mathrm{SiC} / \mathrm{SiAlON}$ and SiAlON/mullite interfaces are $6.4 \mathrm{~J} / \mathrm{m}^{2}$ and the lower limit of $\Gamma_{\text {init }}$ for the mullite/YbDS interface is $6.8 \mathrm{~J} / \mathrm{m}^{2}$. 
Table 13 shows comparison between $\mathcal{G}_{\text {init }}^{\text {th }}$ of the SiC/SiAlON, SiAlON/mullite and mullite/YbDS interface cracks and $\Gamma_{\text {init }}$ of the corresponding interfaces. $\mathcal{G}_{\text {init }}^{\text {th }}$ s of every objective interface crack are smaller than $\Gamma_{\text {init. }}$. This result suggests that the effect of thermal residual stress on the intrinsic fracture toughness for interface crack initiation is sufficiently small. Therefore, in this study, we regard the nominal value as the fracture toughness of interface crack initiation. Table 13 also suggests that the $\mathrm{SiC} / \mathrm{SiAlON}$, SiAlON/mullite and mullite/YbDS interface cracks are not likely to initiate by cooling in the $\mathrm{T} / \mathrm{EBC}$ fabrication process.

Table 13. Comparison between $\mathcal{G}_{\text {init }}^{\text {th }}$ of target interface cracks and fracture toughness for interface crack initiation $\left(\Gamma_{\text {init }}\right)$ of corresponding interfaces.

\begin{tabular}{ccc}
\hline Interface & $\mathcal{G}_{\text {init }}^{\text {th }}\left[\mathbf{J} / \mathbf{m}^{2}\right]$ & $\Gamma_{\text {init }}\left[\mathbf{J} / \mathbf{m}^{2}\right]$ \\
\hline SiC/SiAlON & 0 & $6.4^{1}$ \\
SiAlON/mullite & 0.324 & $6.4^{1}$ \\
Mullite/YbDS & -0.069 & $6.8^{2}$ \\
\hline
\end{tabular}

${ }^{1}$ Approximate value. ${ }^{2}$ Lower limit value.

Figure $13 \mathrm{a}-\mathrm{c}$ show comparisons between $\mathcal{G}_{\text {prop }}^{\text {th }}$ and fracture toughness for interface crack propagation, $\Gamma_{\text {prop }}$, at the $\mathrm{SiC} / \mathrm{SiAlON}$, SiAlON/mullite and mullite/YbDS interfaces. Here, we assumed that fracture surfaces formed by interface crack initiation and propagation were the same and regarded $\Gamma_{\text {prop }}$ as equal to $\Gamma_{\text {init. }}$. As shown in Figure 13a,c, $\mathcal{G}_{\text {prop }}^{\text {th }}$ of the SiC/SiAlON and mullite/YbDS interface cracks are smaller than $\Gamma_{\text {prop }}$ of the corresponding interfaces. The results suggest that these interface cracks are not likely to propagate regardless of initial interface crack length. Figure 13b suggests that, if the T/EBC has an initial length of the SiAlON/mullite interface crack of about $1200 \mu \mathrm{m}$, the crack should propagate instantly because $\mathcal{G}_{\text {prop }}^{\text {th }}$ exceeds $\Gamma_{\text {prop }}$ at the crack length of $1200 \mu \mathrm{m}$. However, delamination along the SiAlON/mullite interface was not observed in the experiment (see Section 3.2). These results suggest that there was no initial crack exceeding the length threshold at the SiAlON/mullite interface.

The results shown in this section reveal that the T/EBC with the proposed layer thicknesses can be fabricated without delamination along interfaces by cooling in the fabrication process. This is confirmed by the result that no delamination along interface is observed as described in Section 3.2.

\subsection{Future Prospects}

In this study, we mainly focused on the mechanical reliability of T/EBC during the cooling process in fabrication. From the practical viewpoint, however, it is also essential to evaluate the mechanical reliability under an operating condition. In general, an EBC is exposed to a thermal cycle condition with a high humidity in operation, which can induce a microstructural change and chemical transformation of the coating layers through a reaction with heated oxygen and water vapor. Consequently, changes in the material properties of each layer due to microstructural change and chemical transformation are crucial to the mechanical state in T/EBC. Thus, it is necessary to evaluate a time dependent ERR by the FEM analysis where changes in material properties over time are incorporated. Furthermore, the interface fracture toughness changes presumably over time owing to microstructural change and chemical transformation, which should also be taken into account for a reliable design of T/EBC. Nevertheless, it is beyond the scope of this paper and will be considered in our future work. 


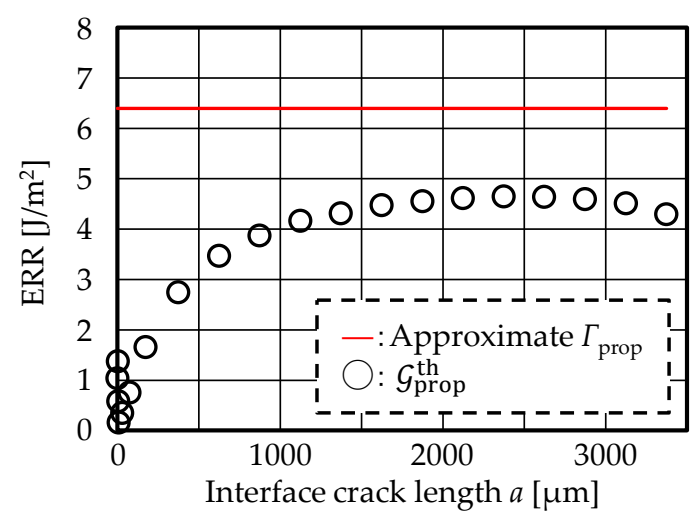

(a)

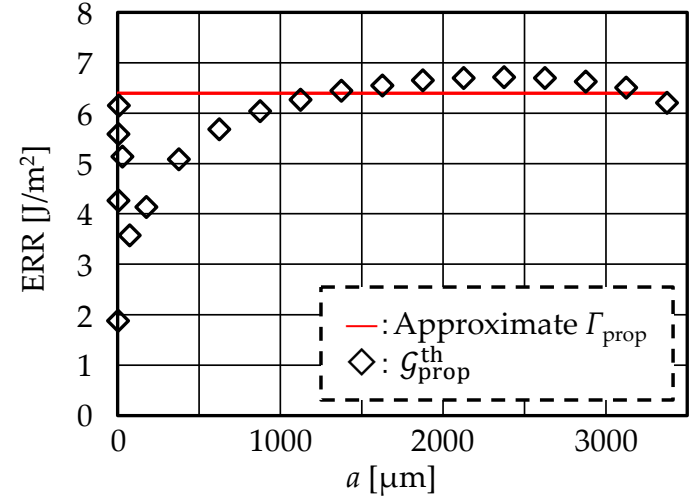

(b)

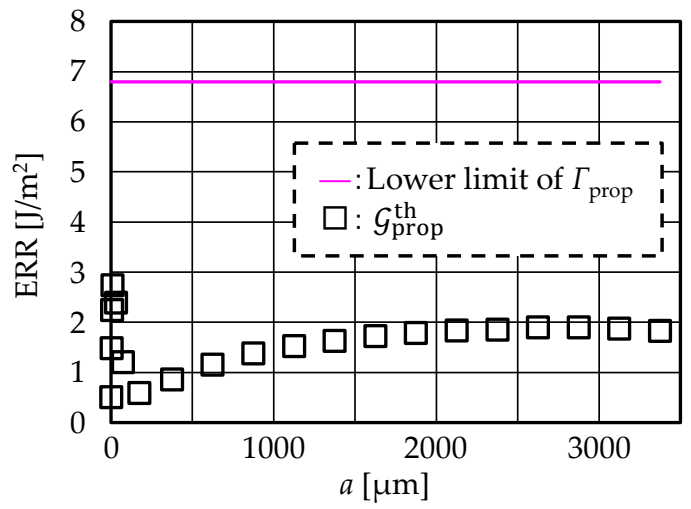

(c)

Figure 13. Comparison between ERR for crack propagation due to thermal stress and fracture toughness for crack propagation at (a) SiC/SiAlON interface, (b) SiAlON/mullite interface and (c) mullite/YbDS interface.

\section{Conclusions}

To assess the mechanical reliability of T/EBC (SiC/SiAlON/mullite/Yb-silicate gradient composition layer/YbMS with porous segment structure) against interface crack initiation and propagation due to thermal stress induced in fabricated process, we carried out FEM analysis to evaluate ERR for interface cracks and performed experiment to obtain interface fracture toughness. Our FEM calculations revealed that $\mathcal{G}_{\text {init }}^{\text {th }}$ of the objective interfaces decreases by making the SiAlON layer thinner and the mullite layer thicker. We fabricated the T/EBC with layer thicknesses within the proposed range $\left(h_{\mathrm{SA}}=5 \mu \mathrm{m}\right.$ and $h_{\mathrm{Mu}}=20 \mu \mathrm{m}$ ) and confirmed no delamination along the interfaces. In the interface fracture test for the fabricated T/EBC, fracture surfaces were found at the SiC/SiAlON and SiAlON/mullite interfaces. We estimated the approximate fracture toughness for the $\mathrm{SiC} / \mathrm{SiAlON}$ and $\mathrm{SiAlON} /$ mullite interfaces and minimum limit of fracture toughness for the mullite/YbDS interface. Comparison between the fracture toughness by the experiment and calculated $\mathcal{G}_{\text {init }}^{\text {th }}$ and $\mathcal{G}_{\text {prop }}^{\text {th }}$ indicated that the fabricated $\mathrm{T} / \mathrm{EBC}$ possesses sufficient mechanical reliability against interface cracks.

Of course, the present study considers only the stress state just after the fabrication process and does not assure the mechanical reliability in operation under thermal cycle with a high humidity, which is regarded as our future work.

Author Contributions: Conceptualization, E.K. and Y.U.; Fabrication of T/EBC, N.Y. and T.Y.; Measurement of material properties, N.Y., T.Y., H.K. and T.A.; FEM analysis, E.K. and A.K.; Interface fracture test, H.K.; Writing-original draft preparation for fabrication process and result, N.Y. and T.Y.; Writing-original draft preparation for FEM analysis and result, E.K. and A.K.; Writing-original draft preparation for interface fracture test procedure and result, H.K.; Writing-review and editing, S.K. and Y.U.; Supervision, H.K., T.A., S.K. and Y.U.; Project administration, S.K.; Funding acquisition, H.K., T.A., S.K. and Y.U. 
Funding: This work was supported by Council for Science, Technology and Innovation (CSTI), Cabinet Office, Japan, through Cross-ministerial Strategic Innovation Promotion Program (SIP), "Structural Materials for Innovation" (Funding agency: JST, Japan Science and Technology Agency).

Acknowledgments: The authors would like to thank Kaori Sakata, Shoko Taniguchi and Takahumi Kawano for technical assistance.

Conflicts of Interest: The authors declare no conflict of interest.

\section{Appendix A. Procedure for Calculating the Temperature-Dependent Material Properties}

\section{Appendix A.1. Young's Modulus, Poisson's Ratio and Shear Modulus}

In this study, Young's moduli $E$ at $303-1673 \mathrm{~K}$ of the $\mathrm{SiC}$ and $\mathrm{SiAlON}$ layers were considered to be identical to that of their bulk, $E_{\text {bulk. }}$ E at the same temperature range of the mullite, YbDS and YbMS layers was estimated from the measured values of coating specimens deposited by the dual EB-PVD process with the same conditions described in Section 2.1, $E_{\text {film. }}$. The outline of the estimation method of $E$ of each layer is shown below;

Step 1: Derivation of an approximation formula of relation between temperature, $T$, and $E_{\text {bulk }}$ of measured values or literature values.

Step 2: Estimation of $E_{\text {bulk }}$ at the temperature range from 303 to $1673 \mathrm{~K}$ based on the approximation formula derived in Step 1.

Step 3: Measurement of $E_{\text {film }}$ at $303 \mathrm{~K}$ of a film/substrate layered specimen.

Step 4: Estimation of temperature dependence of the $E, E(T)$, of the coating layers using the temperature dependence of $E_{\text {bulk }}$ and the ratio of $E_{\text {film }}(303)$ to $E_{\text {bulk }}(303)$ shown in Equation (A1);

$$
E(T)=E_{\text {bulk }}(T) \frac{E_{\text {film }}(303)}{E_{\text {bulk }}(303)}
$$

Es of the SiC and SiAlON layers were estimated through Steps 1 and 2. The values of $E$ of the mullite, YbDS and YbMS layers were estimated through Steps 1-4. Tables A1 and A2 summarize the estimation procedure for each layer at Step 1 and Steps 2-3, respectively. For the Yb-silicate gradient composition layer, $E$ was obtained from Young's moduli of the YbMS and YbDS layers by the following Equation [17]:

$$
E_{\beta: 1-\beta}=\left(E_{\mathrm{YM}}\right)^{\beta}\left(E_{\mathrm{YD}}\right)^{1-\beta}, \beta=0,0.2,0.5,0.8 \text {, and } 1 \text {. }
$$

Here, $\beta$ and $1-\beta$ denote volume content of $\mathrm{YbMS}$ and $\mathrm{YbDS}$, respectively.

Table A1. Estimation procedure of $E$ of SiC, SiAlON, mullite, YbDS and YbMS layers (Step 1).

\begin{tabular}{cccc}
\hline \multirow{2}{*}{ Coating Layer } & \multicolumn{3}{c}{ Step 1 } \\
\cline { 2 - 4 } & Specimen (Bulk) & Measurement Method & Temperature Range $\boldsymbol{T}$ [K] \\
\hline SC & Wafer $^{1}$ & JIS R1602 & $303-1573$ \\
SA & Sintered body $^{2}$ & Resonant method & $303-973$ \\
Mu & Sintered body $^{3}$ & JIS R1602 & $303-1273$ \\
YbDS & Sintered body $^{4}$ & JIS R1602 & $303-1273$ \\
YbMS & Reference [18] $^{*}$ & Reference [18] & $300-1600[18]$ \\
\hline
\end{tabular}

${ }^{1}$ CVD-SiC wafer, ADMAP Inc.. ${ }^{2}$ Raw powder: BSI3-001B, AG Materials Inc.. Sintering condition: $2023 \mathrm{~K}$ for two hours, applied pressure $40 \mathrm{MPa}, P_{\mathrm{N} 2}=0.6 \mathrm{MPa} .{ }^{3}$ Raw powder: KM-101, KCM Corporation. Sintering condition: $1573 \mathrm{~K}$ for fifty hours in air $\rightarrow 2023 \mathrm{~K}$ for five hours in air. ${ }^{4}$ Raw powder: self-build by ultrasonic spray pyrolysis. Sintering condition: $1673 \mathrm{~K}$ for two hours in air $\rightarrow$ Jet mill grinding $\rightarrow 1773 \mathrm{~K}$ for five hours in air. ${ }^{5}$ Resonant method with cantilever bending and torsion mechanism. Dimensions of a specimen are $2 \mathrm{~mm} \times 10 \mathrm{~mm} \times 60 \mathrm{~mm}$. 
Table A2. Detail of estimation procedure of $E$ of $\mathrm{SiC}$, SiAlON, mullite, YbDS and YbMS layers (Steps 2 and 3$)$.

\begin{tabular}{cccc}
\hline \multirow{2}{*}{ Coating Layer } & \multicolumn{2}{c}{ Step 2 } & \multicolumn{2}{c}{ Step 3 } \\
\cline { 2 - 4 } & Approximation Formula & Specimen (Film/Substrate) & Measurement Method \\
\hline $\mathrm{SC}$ & Linear & - & - \\
$\mathrm{SA}$ & Linear & - & - \\
$\mathrm{Mu}$ & $E=E_{0}-F T \exp \left(\frac{-T_{0}}{T}\right)^{1}$ & $\mathrm{Mu} / \mathrm{Mu}$ & Nanoindentation test $^{2}$ \\
$\mathrm{YbDS}$ & $E=E_{0}-F T \exp \left(\frac{-T_{0}}{T}\right)^{1}$ & $\mathrm{YbDS} / \mathrm{YbDS}$ & Nanoindentation test $^{2}$ \\
$\mathrm{YbMS}$ & $E=E_{0}-F T \exp \left(\frac{-T_{0}}{T}\right)^{1}$ & $\mathrm{YbMS} / \mathrm{YbDS}$ & Nanoindentation test $^{2}$ \\
\hline \multicolumn{4}{c}{}
\end{tabular}

The values of $v$ of the SiC, SiAlON and YbDS layers were considered to be identical to those of their bulk. The outline of the estimation procedure of $v$ of each layer at Step 1 is shown in Table A3.

Step 1: Measurement of $v$ of the bulk, $v_{\text {bulk }}$ in some temperature range.

Step 2: Obtainment of $v$ in the temperature range from 303 to $1673 \mathrm{~K}$ by the assumption that $v_{\text {bulk }}$ outside the temperature range in Step 1 was identical to that measured at adjacent temperature.

Table A3. Estimation procedure of $v$ of SiC, SiAlON and YbDS layers (Step 1).

\begin{tabular}{cccc}
\hline \multirow{2}{*}{ Coating Layer } & \multicolumn{3}{c}{ Step 1 } \\
\cline { 2 - 4 } & Specimen (Bulk) & Measuring Method & Temperature Range $\boldsymbol{T}$ [K] \\
\hline SC & Description in Table A1 & JIS R1602 and ASTM C848 & Description in Table A1 \\
SA & Description in Table A1 & Description in Table A1 & Description in Table A1 \\
YbDS & Description in Table A1 & JIS R1602 and ASTM C848 & Description in Table A1 \\
\hline
\end{tabular}

$v_{i j}$ of the anisotropic mullite layer in the temperature range from 303 to $1673 \mathrm{~K}$ was estimated using $v_{i j}$ of the bulk specimen described in Table A1 and $E_{\text {film }}$ of the mullite layer derived from the procedure shown in Table A2. $v$ of the YbMS used in this estimation was literature value [9] and temperature-independent. For the $\mathrm{Yb}$-silicate compositional gradient layers, $v$ was obtained from Young's moduli and bulk moduli, $B$, of YbMS and YbDS by the following equations:

$$
v_{\beta: 1-\beta}=\frac{1}{2}\left(1-\frac{E_{\beta: 1-\beta}}{3 B_{\beta: 1-\beta}}\right), B_{\beta: 1-\beta}=\left(B_{\mathrm{YM}}\right)^{\beta}\left(B_{\mathrm{YD}}\right)^{1-\beta} .
$$

The YbMS anisotropic homogeneous layer is characterized by anisotropic Young's modulus, $E_{i}^{\text {ani }}$, Poisson's ratio, $v_{i j}^{\text {ani }}$, and shear modulus, $G_{i j}^{\text {ani }}(i, j=x, y, z ; i \neq j)$. A method of calculations for these parameters will be discussed in Reference [14]. Shear modulus of mullite layer was estimated by Equation (A4).

$$
G_{i j}=\frac{E_{i} E_{j}}{E_{i}+E_{j}+2 E_{j} v_{i j}} .
$$

Appendix A.2. CTE (Reference Temperature: 1673 K)

$\alpha^{\prime}$ was calculated from CTE at the reference temperature of $303 \mathrm{~K}(\alpha$; evaluated as a function of temperature from experimental measurements) as follows:

$$
\alpha^{\prime}(T)=\frac{\alpha(T) \times(T-303)-\alpha(1673) \times(1673-303)}{(T-1673) \times(\alpha(1673) \times(1673-303)+1)} .
$$

$\alpha$ of the SiC and SiAlON layers was considered to be identical to that of their bulk. The values of $\alpha$ of the sintered bodies and the wafer in the temperature range from 573 to $1673 \mathrm{~K}$ were measured based on JIS R1618. Then, $\alpha$ of the sintered bodies and the wafer at 323-1673 K was estimated by 
extrapolation of the relationship between $\alpha$ and T. $\alpha$ of the mullite, YbDS and YbMS layers at given temperature was estimated using measured values of film/substrate layered specimens deposited with the same conditions as in Section 2.1. The outline of the calculation procedure of $\alpha$ of each layer is described below;

Step 1: Derivation of relationship between strain, $\varepsilon$, and $T$ for each film/substrate layered specimen (described in Table A2), based on digital image correlation method.

Step 2: Approximation of the $\varepsilon-T$ relationship derived in Step 1 by Equation (A6).

$$
\varepsilon=N_{1}(T-303)+N_{2}(T-303)^{2} .
$$

Step 3: Calculation of $\alpha$ in the temperature range from 323 to $1673 \mathrm{~K}$ using the approximation formula derived in Step 2.

The value of $\alpha$ of the $\mathrm{Yb}$-silicate gradient composition layers was obtained by the law of mixture as follows [20]:

$$
\alpha_{\beta: 1-\beta}=\frac{\alpha_{\mathrm{YM}} \beta B_{\mathrm{YM}}+\alpha_{\mathrm{YD}}(1-\beta) B_{\mathrm{YD}}}{\beta B_{\mathrm{YM}}+(1-\beta) B_{\mathrm{YD}}} .
$$

In this study, $\alpha$ of the YbMS anisotropic homogeneous layer was regarded as identical to that of the YbMS dense layer.

\section{Appendix A.3. Creep Properties}

In this study, we assumed that the creep property of each layer follows the strain-hardening law expressed as

$$
\dot{\varepsilon}^{\mathrm{c}}=C \sigma^{n},
$$

where $\dot{\varepsilon}^{\mathrm{c}}$ denotes creep strain rate.

As described in Section 2.2.2, we assumed that creep was negligible for the SiC layer. Creep properties of the SiAlON, mullite, YbDS and YbMS layers were estimated by the method described below;

Step 1: Estimation of $n$ at a given temperature and the average of $n$ within the temperature range from the graph of the true stress and the strain rate derived from literature values and/or measured values. Noted that the average of $n$ was used in the FEM analysis.

Step 2: Estimation of $C$ at a given temperature using the average of $n$, true stress and strain rate derived in Step 1.

Step 3: Estimation of $C$ in the temperature range from 1173 to $1673 \mathrm{~K}$ using $C^{*}$ and $Q / R$ in Equation (A9) based on $C$ versus inverse of $T$ plot derived in Step 2.

$$
C=C^{*} \exp \left(-\frac{Q}{R T}\right)
$$

The estimation method of the creep properties of each layer at Step 1 is shown in Table A4. For the $\mathrm{Yb}$-silicate gradient composition layers, $\mathrm{C}$ and $n$ were obtained as follows:

$$
\begin{gathered}
C_{\beta: 1-\beta}=\left(C_{\mathrm{YM}}\right)^{\beta}\left(C_{\mathrm{YD}}\right)^{1-\beta}, \\
n_{\beta: 1-\beta}=\left(n_{\mathrm{YM}}\right)^{\beta}\left(n_{\mathrm{YD}}\right)^{1-\beta} .
\end{gathered}
$$

The creep property of the YbMS anisotropic homogeneous layer was regarded as identical to that of the YbMS dense layer. 
Table A4. Method of creep property estimation of the SiAlON, mullite, YbDS and YbMS layers (Step 1).

\begin{tabular}{cccc}
\hline \multirow{2}{*}{ Coating Layer } & \multicolumn{3}{c}{ Step 1 } \\
\cline { 2 - 4 } & Specimen & Measurement Method & Temperature Range $\boldsymbol{T}$ [K] \\
\hline SA & Reference [21] & Reference [21] & $1723-1873$ \\
$\mathrm{Mu}$ & Reference [22] & Reference [22] & $1638-1713$ \\
YbDS & Description in Table A1 & Uniaxial compressive creep test ${ }^{2}$ & $1623-1723$ \\
YbMS & Sintered body $^{1}$ & Uniaxial compressive creep test & \\
\end{tabular}

${ }^{1}$ Raw powder: self-build by ultrasonic spray pyrolysis. Sintering condition: $1873 \mathrm{~K}$ for two hours in air $\rightarrow$ Jet mill grinding $\rightarrow 1823 \mathrm{~K}$ for 0.5 hours applied pressure $50 \mathrm{MPa}$ in Ar, $1873 \mathrm{~K}$ for five hours in air. ${ }^{2}$ Dimensions of a specimen are $3 \mathrm{~mm} \times 2 \mathrm{~mm} \times 2 \mathrm{~mm}$.

\section{Appendix B. Preliminary FEM Analyses: Determination of Objective Interfaces and Crack Lengths}

As was explained in Introduction, an interface crack in the T/EBC is likely to occur at interfaces with strong thermal stress concentration due to the difference in the CTEs from the $\mathrm{SiC} / \mathrm{SiC}$ substrate. Here we determined the objective interfaces and crack lengths from the stress distribution obtained by a preliminary FEM analysis. The thermal stress analysis was carried out in the way shown in Section 2.2.2 for the uncracked T/EBC model with the SiAlON and mullite layers both being $25 \mu \mathrm{m}$ thick.

Figure A1 shows the distribution of $\sigma_{x}$ near the interface edge in the constituent layers of the T/EBC after the cooling process. Thermal stress is found to be concentrated particularly at the SiC/SiAlON, SiAlON/mullite and mullite/YbDS interfaces. Thus, we focused on crack initiation and propagation at these objective interfaces in this study.

From the balance of the stress component in the $x$ direction, we deduce $\sigma_{x} \sim 0$ at the interface edge and thus a dominating effect of $\sigma_{y}$ on $\mathcal{G}_{\text {init }}^{\text {th }}$. Therefore, we determined the crack lengths examined to evaluate $\mathcal{G}_{\text {init }}^{\text {th }}$, based on the $\sigma_{y}$ distribution in the vicinity of the interface edge. Figure A2 shows the $\sigma_{y}$ distribution in the coating layers along the $y$ axis at the positions $r_{x}$ distant from the interface edge $\left(r_{x}\right.$ $=0,5,10,60,100,300,500$ and $1000 \mu \mathrm{m})$. The highest level of $\sigma_{y}$ was observed at the interface edge $\left(r_{x}\right.$ $=0 \mu \mathrm{m}$ ) while the $\sigma_{y}$ distribution reduces to a negligible level inside the model. On the basis of the results, we examined the crack lengths of $a=2.5,5.0$ and $7.5 \mu \mathrm{m}$ to evaluate $\mathcal{G}_{\text {init }}^{\text {th }}$. For evaluation of $\mathcal{G}_{\text {prop }}^{\text {th }}$ the crack length $a$ was varied as $a=2.5,5.0,7.5,10,50,100,250, \ldots, 3500 \mu \mathrm{m}$ in increments of $250 \mu \mathrm{m}$ between 250 and $3500 \mu \mathrm{m}$.
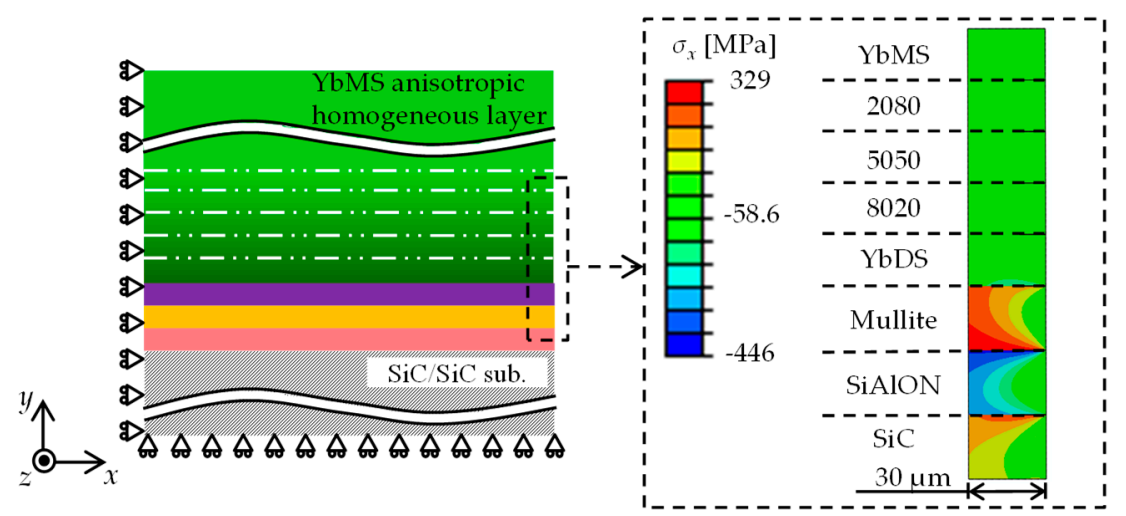

Figure A1. Thermal stress distribution near right interface edge of T/EBC deposited on $\mathrm{SiC} / \mathrm{SiC}$ substrate without interface cracks. 


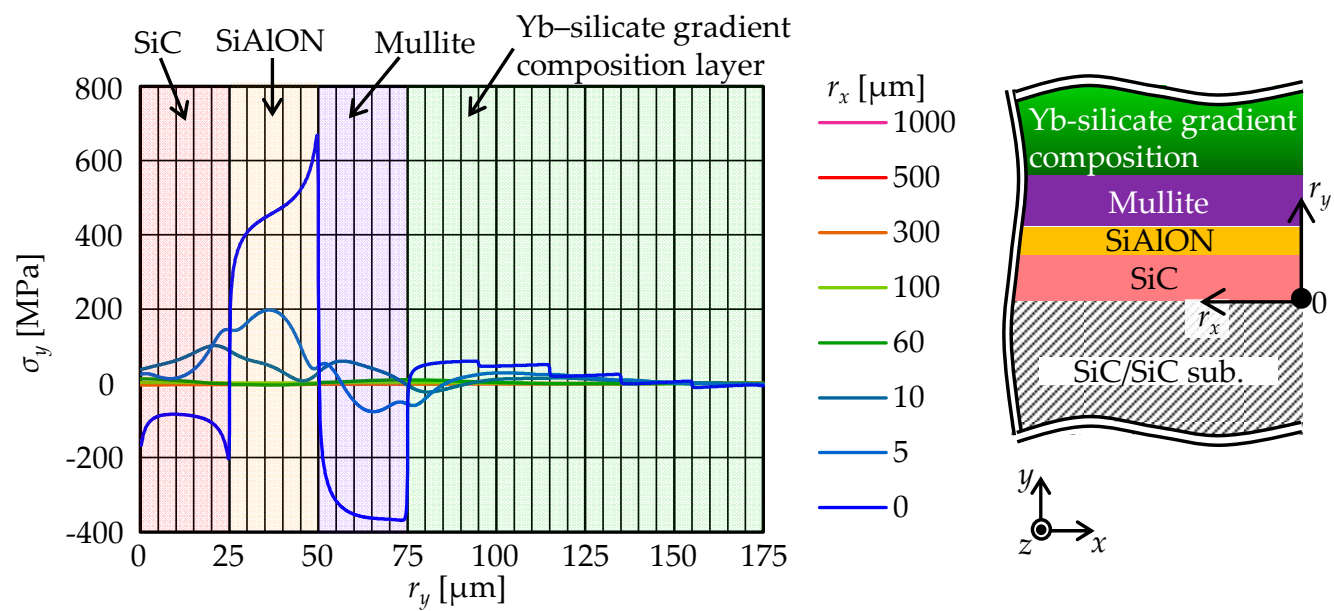

Figure A2. $\sigma_{y}$ distributions in coating layers along the $y$ axis at the positions $r_{x}$ distant from right $\mathrm{SiC} /$ substrate interface edge in $x$ direction.

\section{Appendix C. Derivation Process of Energy Release Rate under Applying Mechanical Loading}

Figure A3 shows the loads and moments applied to the specimen. $P_{b}$ and $M_{b}(b=1,2)$ are the load and moment from surrounding jigs, respectively, and $P$ is the applied load by the pushing plate. Equilibria of forces and moments are given by the following equations, respectively [16,23,24]:

$$
P-P_{1}-P_{2}=0
$$

and

$$
P\left(\frac{h_{\text {coat }}}{2}+h_{\text {sub }}-\delta\right)-M_{1}-M_{2}=0,
$$

where $h_{\text {sub }}$ and $h_{\text {coat }}$ are the thicknesses of the substrate and coating, respectively, and $\delta$ is the distance from the bottom of the substrate to the neutral axis of the specimen. When $L$ is small compared to $h_{\text {sub }}$, large $P_{2}$ and $M_{2}$ can be generated, but in this case these are negligible. The specimen is a multi-layer composite of ten layers including the substrate with different Young's moduli, $E_{p}$, and thicknesses, $h_{p}$ $(p=1,2, \cdots, 10)$, so $\delta$ is given in a quite complicated form. Fortunately, in the loading condition for this test, the load applied to the coating is almost purely compressive parallel to the coating plane and the contribution of moment to the strain energy seems relatively small, thus the Young's modulus of the coating, $E_{\text {coat }}$, and the substrate, $E_{\mathrm{sub}}$, may be simply approximated with the Voigt model in the rule of mixture, respectively,

$$
E_{\mathrm{sub}}=\frac{1}{h_{\mathrm{sub}}} \sum E_{s} h_{s}, E_{\mathrm{coat}}=\frac{1}{h_{\mathrm{coat}}} \sum E_{t} h_{t}, s+t=10,
$$

where $s, t, h_{\text {sub }}$ and $h_{\text {coat }}$ are varied according to the fractured interface. Thus $\delta$ can be obtained as the neutral axis position of a simple two-layer composite (single equivalent coating layer with $E_{\text {coat }}$ and substrate with $E_{\text {sub }}$ ):

$$
\delta=\Lambda h_{\text {coat }}, \Lambda=\frac{1+2 \Sigma \eta+2 \Sigma \eta^{2}}{2 \eta(1+\Sigma \eta)}
$$

where

$$
\Sigma=\frac{E_{\text {coat }}^{\prime}}{E_{\text {sub }}^{\prime}}, \eta=\frac{h_{\text {coat }}}{h_{\text {sub }}}, E_{\text {coat }}^{\prime}=\frac{E_{\text {coat }}}{1-\left(v_{\text {coat }}\right)^{2}}, E_{\text {sub }}^{\prime}=\frac{E_{\text {sub }}}{1-\left(v_{\text {sub }}\right)^{2}} .
$$

$v_{\text {coat }}$ and $v_{\text {sub }}$ are Poisson's ratios of coating and substrate, respectively. 
Energy release rate for the edge crack under an applied load of $P$ is denoted by $\mathcal{G}$ and expressed as [24]

$$
\mathcal{G}=\frac{1}{2 w^{2} E_{\text {coat }}^{\prime}}\left(\frac{P^{2}}{h_{\text {coat }}}\right)+\frac{1}{2 w^{2} E_{\text {sub }}^{\prime}}\left\{-\frac{\left(P_{1}\right)^{2}}{D h_{\text {coat }}}-\frac{\left(M_{1}\right)^{2}}{I\left(h_{\text {coat }}\right)^{3}}+\frac{\left(P_{2}\right)^{2}}{h_{\text {sub }}}+12 \frac{\left(M_{2}\right)^{2}}{\left(h_{\text {sub }}\right)^{3}}\right\} .
$$

Here, $D$ is the dimensionless cross-sectional area and $I$ is the moment of inertia of area written as

$$
D=\frac{1}{\eta}+\Sigma, I=\Sigma\left\{\left(\Lambda-\frac{1}{\eta}\right)^{2}-\left(\Lambda-\frac{1}{\eta}\right)+\frac{1}{3}\right\}+\frac{\Lambda}{\eta}\left(\Lambda-\frac{1}{\eta}\right)+\frac{1}{\eta^{3}} .
$$

$I$ is again calculated assuming that the material system is a two-layer composite with a coating and substrate. Substituting Equations (A12), (A13) and $P=P_{\text {init }}$ into (A17) and ignoring $P_{2}$ and $M_{2}$, Equation (4) is derived.

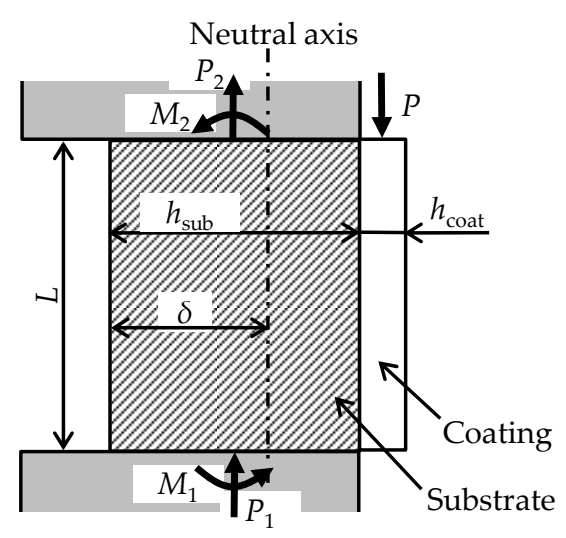

Figure A3. Loads and moments applied to specimen.

\section{References}

1. Pollock, T.M.; Tin, S. Nickel-based superalloys for advanced turbine engines: Chemistry, microstructure and properties. J. Propul. Power 2006, 22, 361-374. [CrossRef]

2. Spitsberg, I.; Steibel, J. Thermal and environmental barrier coatings for SiC/SiC CMCs in aircraft engine applications. Int. J. Appl. Ceram. Technol. 2004, 1, 291-301. [CrossRef]

3. Padture, N.P. Advanced structural ceramics in aerospace propulsion. Nat. Mater. 2016, 15, 804-809. [CrossRef] [PubMed]

4. Opila, E.J. Oxidation and volatilization of silica formers in water vapor. J. Am. Ceram. Soc. 2003, 86, 1238-1248. [CrossRef]

5. Robinson, R.C.; Smialek, J.L. $\mathrm{SiC}$ recession caused by $\mathrm{SiO}_{2}$ Scale volatility under combustion conditions: I, experimental results and empirical model. J. Am. Ceram. Soc. 1999, 82, 1817-1825. [CrossRef]

6. Poerschke, D.L.; Van Sluytman, J.S.; Wong, K.B.; Levi, C.G. Thermochemical compatibility of ytterbia-(hafnia/silica) multilayers for environmental barrier coatings. Acta Mater. 2013, 61, 6743-6755. [CrossRef]

7. Richards, B.T.; Young, K.A.; de Francqueville, F.; Sehr, S.; Begley, M.R.; Wadley, H.N.G. Response of ytterbium disilicate-silicon environmental barrier coatings to thermal cycling in water vapor. Acta Mater. 2016, 106, 1-14. [CrossRef]

8. Klemm, H. Silicon nitride for high-temperature applications. J. Am. Ceram. Soc. 2010, 93, 1501-1522. [CrossRef]

9. Lu, M.-H.; Xiang, H.-M.; Feng, Z.-H.; Wang, X.-Y.; Zhou, Y.-C. Mechanical and thermal properties of $\mathrm{Yb}_{2} \mathrm{SiO}_{5}$ : A promising material for T/EBCs applications. J. Am. Ceram. Soc. 2016, 99, 1404-1411. [CrossRef]

10. Kitaoka, S.; Matsudaira, T.; Yokoe, D.; Kato, T.; Takata, M. Oxygen permeation mechanism in polycrystalline mullite at high temperatures. J. Am. Ceram. Soc. 2017, 100, 3217-3226. [CrossRef] 
11. Wada, M.; Matsudaira, T.; Kawashima, N.; Kitaoka, S.; Takata, M. Mass transfer in polycrystalline ytterbium disilicate under oxygen potential gradients at high temperatures. Acta Mater. 2017, 135, 372-381. [CrossRef]

12. Kitaoka, S.; Matsudaira, T.; Wada, M.; Yokoi, T.; Yamaguchi, N.; Kawashima, N.; Ogawa, T.; Yokoe, D.; Kato, $\mathrm{T}$. Mass transfer in $\mathrm{Yb}$ silicates under oxygen potential gradients at high temperatures. AMTC Lett. 2019, 6, 150-151.

13. Kitaoka, S.; Matsudaira, T.; Kawashima, N.; Yokoe, D.; Takata, M. Structural stabilization of mullite films exposed to oxygen potential gradients at high temperatures. Coatings 2019, 9, 630. [CrossRef]

14. Kawai, E.; Kubo, A.; Umeno, Y. Homogenization method for calculating energy release rate in environmental barrier coatings with columnar layer for ceramics. manuscript in preparation.

15. The Society of Materials Science. Strength and Fracture of Materials, 4th ed.; The Society of Materials Science: Kyoto, Japan, 2011; p. 144. (In Japanese)

16. Aoki, Y.; Inoue, J.; Kagawa, Y.; Igashira, K. A simple method for measurement of shear delamination toughness in environmental barrier coatings. Surf. Coat. Technol. 2017, 321, 213-218. [CrossRef]

17. Kagawa, Y.; Hatta, H. Tailoring Ceramic Composites, 1st ed.; Agne Shofusha: Tokyo, Japan, 1990; pp. $96-97$. (In Japanese)

18. Tian, Z.; Zheng, L.; Wang, J.; Wan, P.; Li, J.; Wang, J. Theoretical and experimental determination of the major thermo-mechanical properties of $\mathrm{RE}_{2} \mathrm{SiO}_{5}(\mathrm{RE}=\mathrm{Tb}, \mathrm{Dy}, \mathrm{Ho}, \mathrm{Er}, \mathrm{Tm}, \mathrm{Yb}, \mathrm{Lu}$, and $\mathrm{Y})$ for environmental and thermal barrier coating applications. J. Eur. Ceram. Soc. 2016, 36, 189-202. [CrossRef]

19. Wachtman, J.B., Jr.; Tefft, W.E.; Lam, D.G., Jr.; Apstein, C.S. Exponential temperature dependence of Young's modulus for several oxides. Phys. Rev. 1961, 122, 1754-1759. [CrossRef]

20. Turner, P.S. Thermal-expansion stresses in reinforced plastics. J. Res. Natl. Bur. Stand. 1946, 37, $239-250$. [CrossRef]

21. Chihara, K.; Hiratsuka, D.; Tatami, J.; Wakai, F.; Komeya, K. High-temperature deformation of $\alpha$-SiAlON nanoceramics without additives. Scr. Mater. 2007, 56, 871-874. [CrossRef]

22. Okamoto, Y.; Fukudome, H.; Hayashi, K.; Nishikawa, T. Creep deformation of polycrystalline mullite. J. Eur. Ceram. Soc. 1990, 6, 161-168. [CrossRef]

23. Suo, Z.; Hutchinson, J.W. Interface crack between two elastic layers. Int. J. Fract. 1990, 43, 1-18. [CrossRef]

24. Hutchinson, J.W.; Suo, Z. Mixed mode cracking in layered materials. In Advances in Applied Mechanics; Hutchinson, J.W., Wu, T.Y., Eds.; Elsevier: Amsterdam, The Netherlands, 1991; Volume 29, pp. 63-191. 